K., Üb. d. Lymphapparat d. Harnleiters. Arch. f. Anat. u. Physiolog. Anat. Abteil. S. 1, 1903. 33. S a m s ch in, A., Beobachtungen üb. d. Funktion d. Ureteren an einer Frau mit großer Rektovesikovaginalfistel. Ztlbl. f. Gynäk. 1887, Nr. 19, S. 297. - 34. S a p p e y, Traité d'anatomie: déscriptive 1889, Tom. IV, S. 509. - 35. S e h w a l b e, G., Zur Anat. d. Ureter. Anat. Anz., Ergänzungsheft zum 12. Bd., S. 155, 1896. - 36. S e n a t o r, H., Die Erkrankungen d. Nieren Nothnagels spez. Path. u. Ther., Bd. XIX, 1. H., S. 322-324. Wien 1896. - 37. S o $1 \mathrm{~g}$ e r, B., Zour Kenntnis d. spindelförm. Erweiterungen d. menschl. Harnleiters. Anat. Anz. Bd. 12, S. 347, 1896. - 38. T e i c h m an n, L., Das Saugadersystem, Leipzig 1861. - 39. T ol d t, Lehrb. d. Gewebelehre 1884, S. 502. - 40. S t ö h r , Ph., Lehrb. d. Histologie, Jena 1906, S. 298-299. 41. T u chmann, Die Diagnose d. Blasen- u. Nierenkrankh. mittels d. Harnleiterpinzette, Berlin 1887. - 42. Un r u h, Ưb. Blutungen im Nierenbecken u. in d. Ureteren bei Pocken. Arch. f. Heilk. 1872. - 43. W a r s c h a u e r, E., Beobacht. aus d. Nieren- u. Ureteren-Physiolog., Berlin. KJ.W. 1901, Nr. 15, S. 399. - 44. W e i c h s el b a u m, Allgem. Wien. med. Zeit. 1881, Nr. 35, S. 346. - 45. W il d b o l z, Folia urologica Bd. III, 1909. - 46. Z i e g l e r, E., Lehrb. d. spez. path. Anat., Jena 1902, S. 831 - - 47. Z u ck er k a n d l, O., u. F r it s c h, A. v., Handb. d. Urologie Bd. I u. II, S. 354 u. 601, Wien 1904/5. - 48. D e r s e 1 b e, Die lokalen Erkrankungen d. Harnblase. Nothnagels Spez. Path. u. Ther. Bd. XIX, 2. H., S. 2. Wien 1899.

\title{
IV. \\ Die Zerstörung der roten Blutkörperchen in der Milz und der Leber unter normalen und pathologischen Ver- hältnissen.
}

\author{
Von \\ Dr. med. Johann Lintwarew, \\ Prosektor am Alexanderhospital zu Saratow.
}

(Hierzu Taf. II, III, IV.)

Seit dem Erscheinen der Arbeit von $Q \mathrm{u}_{\text {in }} \mathrm{cke}^{1}$ gilt es als feststehend, daß beim normalen erwachsenen Menschen die roten Blutkörperchen zum größten Teil in der Leber zugrunde gehen und die Erythrozyten bei ihrem Zerfall das Material für die Gallenabsonderung liefern, indem das Blutpigment sich in Gallenpigmente umwandelt.

Des weiteren wurde erwiesen, daß der Zerfall der roten Blutkörperchen auch in der Milz und dem Knochenmark stattfindet, da in diesen Organen Zellen gefunden werden, die rote Blutkörperchen enthalten. Quincke meinte, daß die roten Blutkörperchen auch in den Leberkapillaren von den weißen Blutkörperchen verschlungen werden.

Diese Arbeiten ließen jedoch die Frage völlig unaufgeklärt - bis zum heutigen Tage sind darüber keinerlei Angaben in der Literatur vorhanden -, auf welche Weise die Leberzellen die Zerfallprodukte der roten Blutkörperehen in sich aufnehmen? Denn selbst die größte Verlangsamung der Blutzirkulation in der Leber vorausgesetzt, muß doch die Durchwanderung der Formelemente des Blutes aus der Peripherie der Leberläppchen nach dem Zentrum zu bloß nach Bruchteilen einer Sekunde gemessen werden. Es muß doch jedes Leberläppchen in bezug auf seine Blutversorgung als selbständiges Element betrachtet werden, zu dem das. 


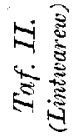
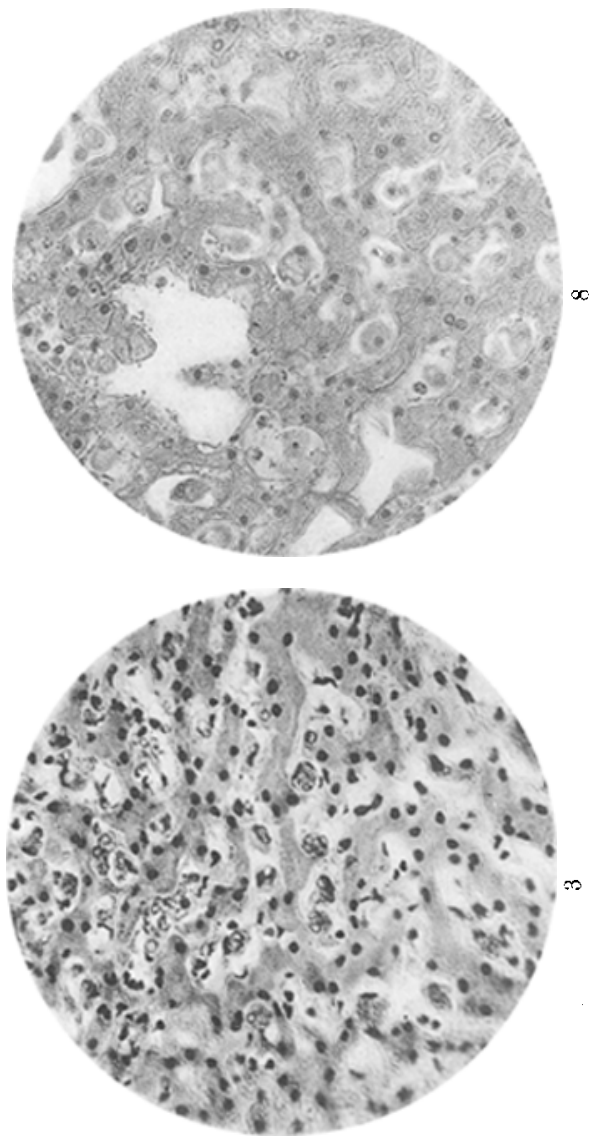

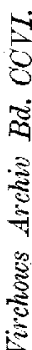
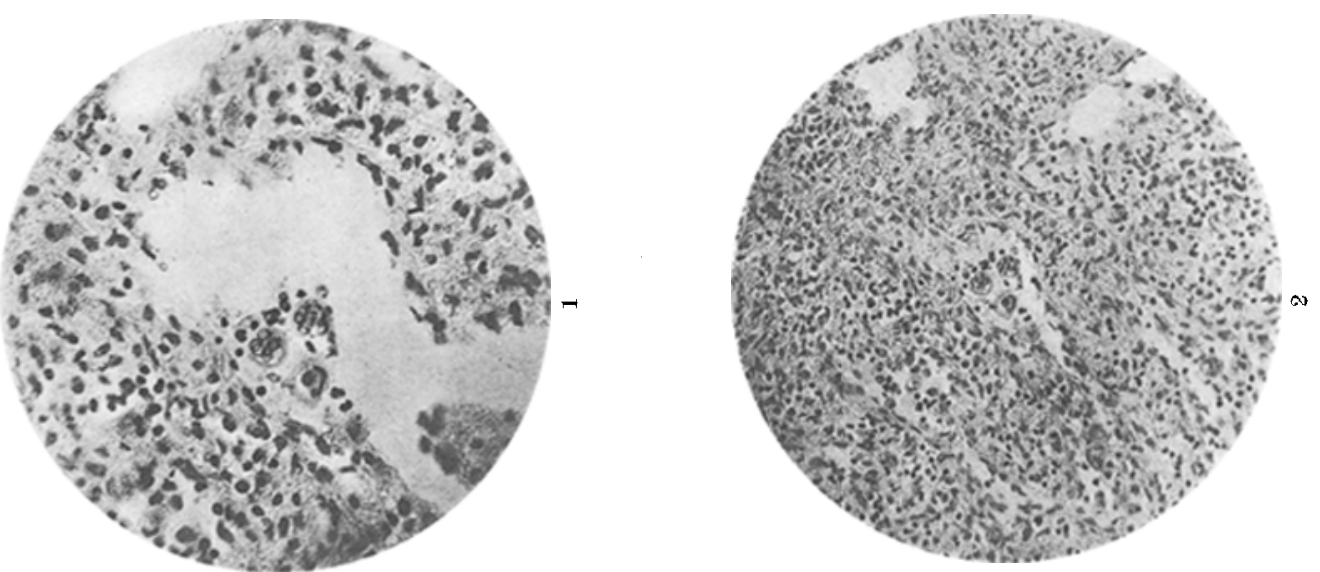
Virchor's Archio, Bd.CCVI.
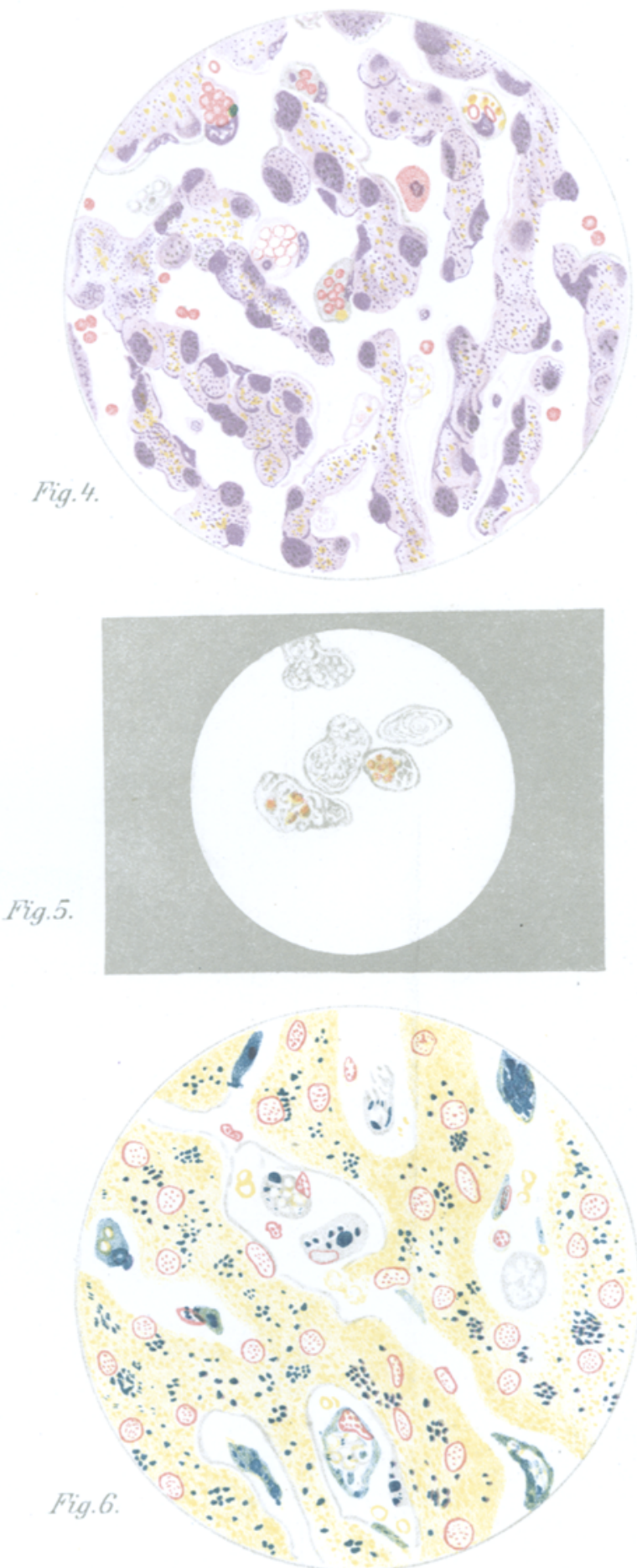

Taf.III.
(Lintrowrem) 


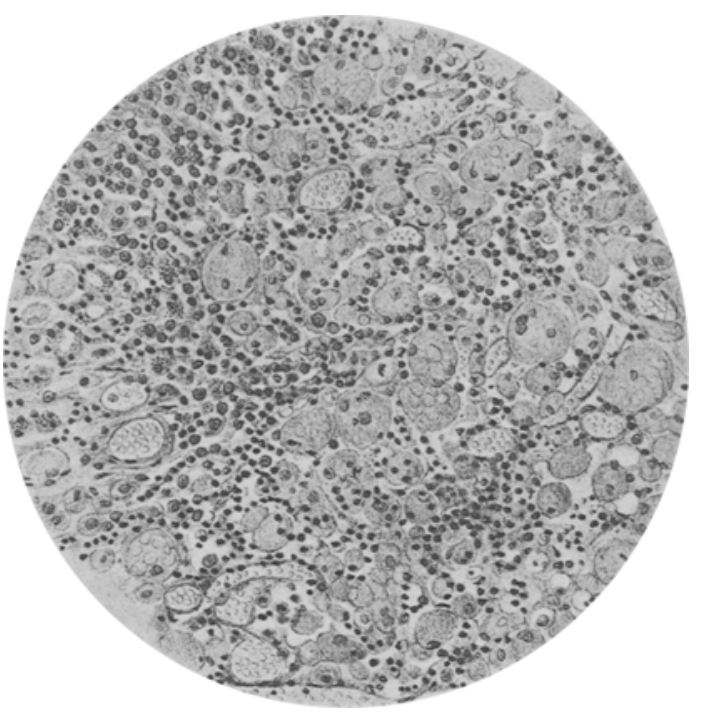

10

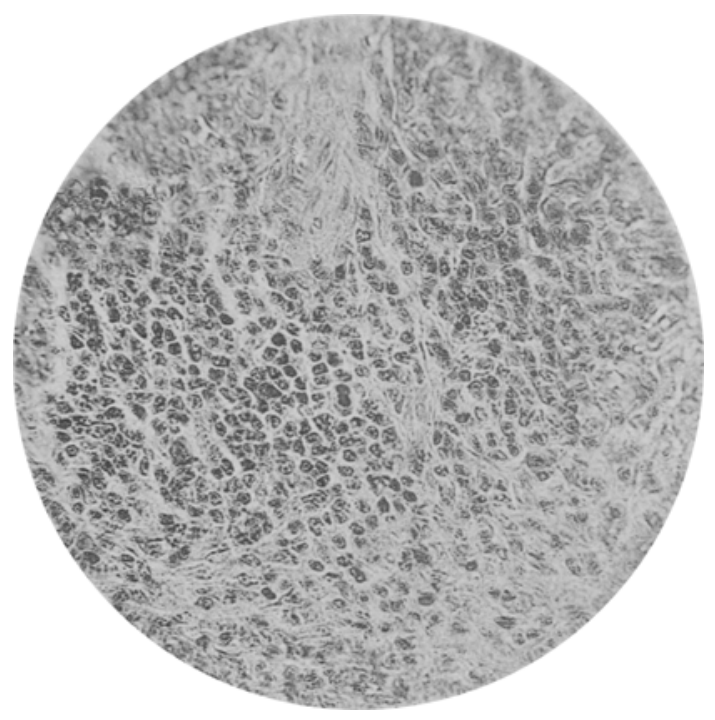

12

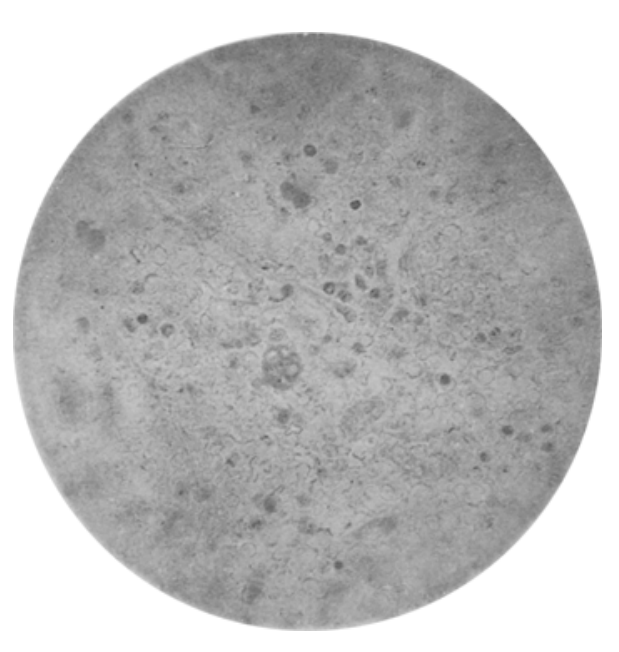

11

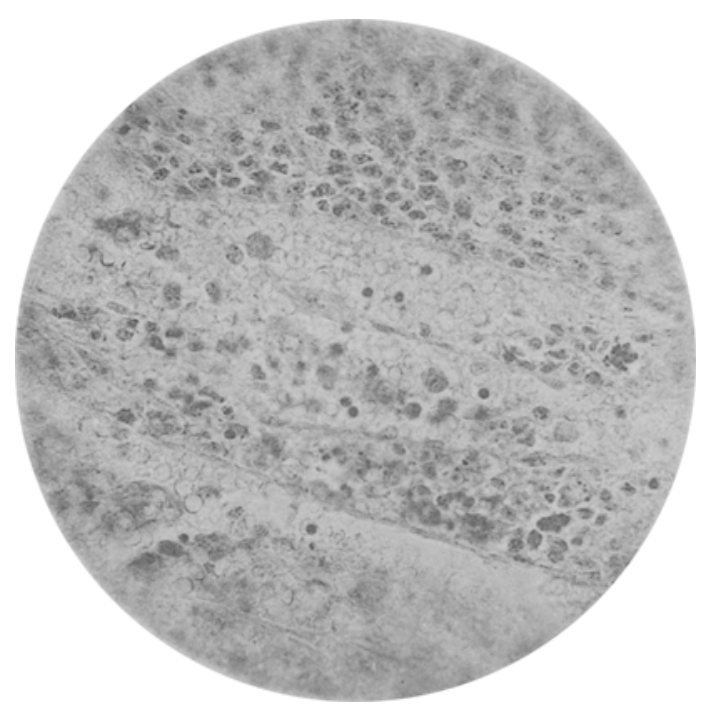


Blut in geschlossenen Gefäßen (Venula portae s. interlobularis) hinströmt und vom Zentrum des Läppchens (Venula centralis) und weiterhin in geschlossenen Röhren abfließt. Man kann sich nicht vom rein, physikalisch-chemischen Standpunkt aus vorstellen, auf welche Weise, während dieses sehr kurzen Zeitraumes, die roten Blutkörperchen zugrunde gehen und ihre Zerfallsprodukte den Leberzellen abgeben könnten. Da jedoch die Tatsache der Aufnahme des Hämoglobins von seiten der Leberzellen keinem Zweifel unterliegt (das Hämosiderin kann immer in der Leber nachgewiesen werden), so müssen wir bereits a priori voraussetzen, daß Bedingungen vorhanden sind, welche die roten Blutkörperehen in den Leberkapillaren zurückhalten, damit die Leberzellen an ihnen ihre zerstörende Tätigkeit entfalten und die dabei entstehenden Zerfallsprodukte aufnehmen können.

Die Untersuchung eines Falles von Anämie bei der B a n t i schen Krankheit (Anaemia megalosplenica cum cirrhosi hepatica) gab uns die Möglichkeit, diejenigen recht einfachen Hilfsvorrichtungen des Organismus kennen zu lernen, vermittels welcher die Zerstörung und weitere Verarbeitung der roten Formelemente des Blutes in der Milz und der Leber stattfindet. In Anbetracht der wichtigen Resultate, die bei dieser Untersuchung gewonnen wurden, erlaube ich mir das betreffende Sektionsprotokoll (19. November 1910) wiederzugeben:

A u B e re Besichtigung. Kräftiger Körperbau, beträchtliche Abmagerung, blasse, gräuliche Hautfarbe; die Schleimhäute blaß, die Konjunktiven leicht ikterisch. Pupillen nicht weit. Die Thoraxapertur breit, der Leib nicht gespannt, etwas eingezogen; an der Außenseite der Knöchel ein geringes Ödem des Unterhautzellengewebes. An den abhängenden Partien eine leichte rötliche hypostatische Verfärbung. Die Leichenstarre gering.

ÄuBere Besichtigung der Brust-und Leibeshöhle. Das Omentum ist nicht angewachsen, fettarm, die Darmschlingen nicht aufgetrieben, der untere Rand der Milz befindet sich einen Querfinger unterhalb des Nabels, der Leberrand entspricht dem Rande der falschen Rippen (in der Maxillarlinie). In der Leibeshöhle befindet sich gegen 1 Liter einer serösen durchsichtigen Flüssigkeit. Die Diaphragmakappe entspricht beiderseits dem unteren Rande der fünften Rippe. Die Rippenknorpel sind verknöchert. Das Herzdreieck ist wenig überlagert. In der linken Pleurahöhle befindet sich ungefähr ein Glas einer serösen Flüssigkeit; die Lunge ist frei. Die rechte Lunge ist am hinteren und Seitenrande verwachsen; der untere Lappen ist frei; im rechten Pleuraraum sind einige EBlöffel eines serösen Transsudates. In der Höhle des Perikardiums etwa 100,0 einer serösen Flüssigkeit.

Brusthöhle. Die Lungen sind emphysematös, das Gewebe ist blutarm und ödematös; in den hinteren unteren Teilen Erscheinungen einer herdförmigen hypostatischen Pneumonie.

Das Herzvolumen ist etwas gering, der linke Ventrikel nicht kontrahiert, das subepikardiale Zellgewebe ist schleimig ödematös. Die Koronararterien sind geschlängelt, ihre Wände sind sklerotisch verdickt, was sich bereits ohne Eröffnung der Gefäße konstatieren läßt. Der Herzmuskel ist bräunlich, etwas getrübt, nicht schlaff. Die Ränder der Trikuspidalis sind leicht verdickt. In den rechten Herzhöhlen befinden sich in geringerer Menge Fibringerinnsel und flüssiges Blut. Die Bikuspidal- und Semilunarklappen des linken Herzens weisen keine Veränderungen auf, in den Höhlen befinden sich wenige gemischte Blutgerinnsel. Am Aortenbogen geringe sklerotische Veränderungen der Intima.

B a u chhöhle. Die Milz ist groß (Längendurchmesser 24,5 cm, Breitendurchmesser $12 \mathrm{~cm}$, Dicke 5,5 cm, Gewicht $845 \mathrm{~g}$ ); die Kapsel dünn, nicht sehr gespannt. Das Organ ist elastisch, mäßig fest. Die Schnittfläche ist glatt, glänzend, die Pulpa läßt sich wenig abstreifen. Das Gewebe 
ist hellrot, überall von gleichmäßiger Farbe; die Trabekel sind deutlich ausgesprochen, die M al pighischen Körperehen wenig sichtbar. Die Milzarterie ist stark sklerosiert. Auf der Intima der Milzvene befinden sich geringe sklerotische Plaques. Die linke Niere ist mäßig groß; die Kapsel läßt sich ohne Verletzung des Gewebes abziehen, die Rinde ist etwas breit, von grauroter Farbe. Die Pyramiden sind dunkler als die Rinde. Die rechte Niere weist dieselben Verhältnisse auf, nur ist die Kapsel stellenweise mit der Rinde verwachsen. Die Nierenbecken, Ureteren und Harnblase sind ohne Véränderung. Die Leber ist mäßig groß, und zwar beschränkt sich die Vergrößerung auf den rechten Lappen. Der linke Lappen ist klein, längs dem linken Rande des Lig. suspensorium hepatis verläuft eine reeht tiefe atrophische Rinne, ohne daß das Gewebe irgendwelche Narben aufweist. Die Oberfläche der Leberränder ist klein-höckerig, an den konvexen Teilen glatt. Das Gewebe knirscht beim Schneiden, die Oberfläche der Schnittfläche an den Randpartien: des Organs ist körnig infolge einer ringförmigen Entwicklung von Bindegewebe. Die Zentralvenen sind mit Blut prall gefüllt. Die Läppchen sind deutlich zu unterscheiden, da ihr Zentrum bräunlich rot gefärbt ist, während die Peripherie heller erscheint. In der Gallenblase befinden sich gegen 30 g einer grüngelblichen flüssigen Galle; die Schleimhaut ist ohne Veränderungen; Schleim nicht. vorhanden. Das Gewicht der Leber beträgt $1630 \mathrm{~g}$. Die Schleimhaut des Magens ist leicht ödematös, körnig, von graurötlicher Farbe. Die Sehleimhaut des Duodenums ist hyperämisch, die Ausmündungsstelle des Gallenganges ist offen. Die Schleimihaut des unteren Abschnittes des Dünndarms. ist hyperämisch und weist zahlreiche oberflächliche kleine katarrhalische Geschwüre auf. Die Schleimhaut des Dickdarms ist etwas verdickt, hyperämisch mit Schleim bedeckt; Geschwüre sind nicht vorhanden. Einige Mesenterialdrüsen sind von der Größe einer Haselnuß, von nicht fester Konsistenz, auf dem Durchschnitt erscheint ihr Gewebe hyperämisch, grau-rosa-rot. Das Knochenmark der Oberschenkel und der Rippen ist rot.

Epikrisis. Anaemia. Icterus levis. Emphysema pulmonum. Pneumonia hypostatica bilateralis. Atrophia fusca musculi cordis. Sclerosis arcus aortae et arteriarum coronar. cordis. Splenomegalia. Cirrhosis hepatis interstitialis partialis. Cyanosis hepatis. Nephritis interstitialis chronica. Entero-colitis catarralis. Ascites. Diagnosis anatomica: morbus Bantii.

Patient war 47 Jahre alt. Der Beginn der-Krankheit vor etwa 6 Jahren, als der Patient sowie die Ärzte eine Vergrößerung der Milz wahrzunehmen begannen. Bei der Blutuntersuchung, die ungefähr zwei Monate vor dem Tode des Patienten ausgeführt wurde, ergaben sich die Erscheinungen einer stark ausgesprochenen Anämie: die Zahl der roten Blutkörperchen - 1665000 , der weißen 8158; Hämoglobin - 55\%. Die Temperatur stieg zeitweise bis auf 38,5 bis $38,9^{\circ} \mathrm{C}$.. war unregelmäßig. Ein Aszites ließ sich erst zehn Tage vor dem Todê zum ersten Male nachweisen. Ikterus seit längerer Zeit vorhanden. Angaben über Syphilis sind in der Anamnese nicht vorhanden; direkte Hinweise auf eine Erkrankung an Malaria fehlen.

Die roten Blutkörperchen waren verändert: es fanden sich viele Zyanophile (polychromatophile), nicht selten Makro- und Mikrozyten, auch Krüppelformen - Poikilozyten; die letzteren jedoch in geringer Anzahl. Erytroblasten wurden nicht gefunden.

Zweeks mikroskopischer Untersuchung wurden Stückchen aus der Milz und der Leber in Azeton gelegt. Dieses Fixationsmittel hat sehr große Vorzüge einerseits wegen der Schnelligkeit, mit der die Präparate gehärtet werden, andrerseits aber deshalb, weil dabei die Formelemente des Blntes sich vorzüglich konservieren und das Hämoglobin aus den Erythrozyten überhaupt nicht ausgelaugt wird, was bei der Fixation mit Formalin oder formalinhaltigen Flüssigkeiten zu. geschehen pflegt. Leider muß ich hier konstatieren, daB fast alle pathologisch-anatomischen und histologischen Präparate unserer Sammlung mit Hilfe von Formalin hergestellt und daher zum Studium der roten Formelemente des Blutes völlig ungeeignet sind.

Um das letztere zu beweisen, habe ich folgendes kleine Experiment angestellt: ein Schnittpräparat, das in Azeton fixiert wurde und nach der Färbung mit Azureosin nach G i e $\mathrm{m}$ s a sehr. 
schön die roten Blutkörperchen erkennen lieB, wurde auf zwei Wochen in eine 4prozentige Lösung von Formalin gelegt und daraufhin mit derselben Farbe behandelt. Wir konnten jetzt keinen einzigen Erythrozyten mehr finden, der die rosarote Farbe des Eosins wahrnehmen ließ und die Zellen, welche die roten Blutkörperchen in ihrem Protoplasma eingeschlossen hatten, schienen Vakuolen zu enthalten, die alle von gleichmäßiger Größe den roten Blutkörperchen entsprachen. Wir erhielten also das Bild der sogenannten wabigen Vakuolisation. Dabei kommt das zarte Protoplasma vieler vakuolisierter Zellen sehr undeutlich zum Vorschein und kann bei der mikroskopischen Untersuchung übersehen werden, da diese Zellen für Detritus gehalten werden können.

Ich bin mit Absicht etwas länger auf die Mängel der Formalinfixation eingegangen, weil ich der Meinung bin, daß die vorzüglichen Bilder, die ich von meinen Präparaten erhalten habe, bloß deshalb von den anderen Autoren nicht mit ähnlicher Schärfe gesehen wurden, weil sie sich der durchaus mangelhaften Fixierung und Konservierung der Präparate in Formalin bedient haben, welch Verfahren bald 20 Jahre lang in unserer Mikroskopiertechnik so allgemein verbreitet ist.

Dem Mangel an frischem pathologisch-anatomischen Material konnte leider nicht durch die sehr reichhaltige Präparatensammlung in unserem Krankenhause abgeholfen werden wegen der Konservierung derselben in Formalin. Ich muß gestehen, daß dieser Umstand uns die Arbeit sehr ersehwert hat.

Nach diesen einleitenden Bemerkungen gehe ich nun über zur Beschreibung der mikroskopischen Befunde in den Milz- und Leberpräparaten bei der B a n t i schen Krankheit, die den Ausgangspunkt unserer weiteren Beobachtungen bildeten.

Bei dem Studium der mikroskopischen Bilder aus der Milz fallen uns vor allen Dingen die zahlreichen großen Zellen auf, die mit roten Blutkörperchen ganz ausgefüllt sind. Diese Zellen befinden sich zum größten Teil innerhalb der erweiterten Blutsinusse der Milz (s. Taf. II, Fig. 1), besitzen ein feinkörniges lockeres Protoplasma und einen recht großen bläschenförmigen Kern mit sehr zartem Chromatinnetz. Nicht alle Zellen sind von gleicher Größe und das Schwanken in der Größe (von 14 bis $60 \mu$ ) ist von der Zahl der in ihnen eingeschlossenen Erythrozyten ahhängig: je mehr sie in der Zelle vorhanden sind, um so größer erscheint dieselbe, wobei die klein. sten Zellen diejenigen sind, die noch keine Erythrozyten aufgenommen haben. Solcher gibt es aber wenige. Das Protoplasma dieser Elemente färbte sich gut mit Eosin rosaviolett in verschiedenen Abstufungen. Die Zellen haben meistenteils einen Kern, mitunter zwei, drei und mehr. Die Zahl der Zellen ist so groß, daß das Lumen der erweiterten Venen von ihnen mitunter völlig ausgefüllt wird und wir dann, dank der Ähnlichkeit mit den Epithelzellen, ein Bild erhalten, welches, wie bereits $\mathrm{Banti^{2 }}$ bemerkt hat, an die Krebsalveolen erinnert. Die soeben beschriebenen Zellen kommen mitunter auch zwischen den Elementen der Pulpa vor, jedoch verlieren hier ihre Kerne meistenteils die Fähigkeit sich zu färben und gehen zugrunde. Kernlose oder zerfallende Zellen kommen auch in den Lumen der Sinus und der Venen vor, jedoch zeigt eine große Zahl der Zellen, die in den GefäBen liegen, keine Zeichen von Zerfall. Es ist interessant, daß sich die größten Anhäufungen der oben beschriebenen Zellen in der Nähe und um die Malpighischen Körperchen der. Milz vorfinden. Diese eigenartigen Elemente enthalten, wie gesagt, in ihrem Körper rote Blutkörperchen in wechselnder Anzahl. Einige enthalten bis zu 50 Erythrozyten, andere 1 bis 2 Körperchen. Die Zelle, die viele Erythrozyten enthält, hat eine bläschenförmige Gestalt; ihr Protoplasma umgibt den Inhalt in Form einer dünnen Hülle; an einer Verdichtung desselben sieht man den verdickten, meistenteils sichelförmigen Kern, Solch eine Zelle erinnert sehr an eine Fettzelle, bloß mit dem Unterschied, $\mathrm{daB}$ an Stelle der großen Fettropfen wir hier eine große Anhäufung von Erythrozyten haben. Im Querdurchschnitt sieht solch eine Zelle einem Ring mit einem Stein ähnlich, wobei dem Stein der Kern entspricht, während an der Innenseite des Ringes die roten Blutkörperchen gelagert sind. 
Die roten Blutkörperchen, die von diesen $\mathrm{Eryth} \mathbf{r}$ o $\mathrm{pha}_{\mathrm{g} \mathrm{e}} \mathbf{n}^{1}$ ) der Milz verschlungen worden sind, erscheinen meistenteils unverändert in ihren morphologischen Eigenschaften. Sie färben sich ebenso gut mit Eosin, wie die Erythrozyten, die nebenan liegen und nicht in Zellen eingeschlossen sind, haben in der Mitte die charakteristische Delle und einen walzenförmigen Rand, sind nicht gekörnt - mit einem Wort: sie unterscheiden sich in keiner Beziehung von den normalen. Sie sind bloß etwas von der Seite eingedrückt, wenn ihrer mehrere zusammenliegen, so daß die Gruppe der Erythrozyten in den Zellen einer Bienenwabe ähnlich sieht.

Im Gegensatz dazu befinden sich in anderen Erythrophagen rote Blutkörperchen, die bereits in verschiedenem Grade die Fähigkeit, sich mit Eosin zu färben, verloren haben, während andere bereits völlig zerfallen sind und Körnchen eines braunroten Pigments vorstellen, die in den ebenfalls zerfallenden Erythrophagen liegen. Dieser Vorgang des totalen Zerfalls der Zellen, die die roten Formelemente des Bluts in der Milz enthalten, ist, wie gesagt, in unserem Fall wenig ausgesprochen; die zerfallenden Elemente befinden sich hauptsächlieh in der Milzpulpa, doch sind hier die Erythrophagen nur wenig vertreten.

Wie enorm groß dieser Vorgang der Aufnahme der roten Blutkörperchen von seiten der Milzzellen ist, geht aus folgender Berechnung hervor. In jedem Gesichtsfelde kann man bei einer Vergrößerung von 400 bis $500 \mathrm{im}$ Durchschnitt 8 bis 10 Erythrophagen zählen (Fig. 2, Taf. II). Wie viele Millionen von solchen Gesichtsfeldern könnten wir jedoch bekommen, wenn wir die gesamte bis auf $845 \mathrm{~g}$ vergrößerte Milz in einzelne Schnitte zerlegen würden! Und wenn dieser enorme Verlust an roten Blutkörperchen von den blutbildenden Organen (Knochenmark) nicht fortwährend ersetzt würde, so wäre bereits in einigen Tagen von den 26 bis 30 Milliarden Erythrozyten, die ein Mensch von mittlerem Gewicht besitzt, kein einziges rotes Blutkörperchen mehr vorhanden.

Als Hauptort, an dem dieser massenhafte und vollständige Zerfall der Erythrophagen samt ihrem Inhalt stattfindet, müssen wir natürlicherweise die Leber ansehen, da die Milzvene in die Pfortader einmündet und ihr Blut, nachdem es sich mit dem Blut der übrigen Wurzeln der Vena portae vermiseht hat, die Leberläppehen umspült.

Selbstredend müssen wir, da wir innerhalb der Milzsinus und -venen so viele Erythrophagen finden, dieselben auch in den Leberkapillaren nachweisen können.

Das histologische Bild der Schnitte aus der Leber, ebenfalls nach Gi e m s a gefärbt, ist wunderbar (Fig. 3, Taf. II).

Die peripherischen Teile der nur wenig erweiterten Kapillaren sind mit Erythrophagen vollgepfropft, und hier ist ihre Anzahl so groB, daß es Gesichtsfelder gibt, an welchen das Zählen dieser Elemente ohne besondere Vorrichtungen sehr erschwert ist.

Die Eigenschaften der Erythrophagen, die wir in der Leber wahrnehmen (Fig. 4, Taf. III), sind dieselben wie in der Milz, und wir erkennen diese Elemente auf den ersten Blick: es sind dieselben großen Zellen mit roten Blutkörperchen beladen. Der Unterschied der in der Leber vorkommenden Erythrophagen von denjenigen der Milz besteht darin, daß wir in der ersten sehr viele zerfallende Formen finden: bei den einen ist der Kern nicht mehr erkennbar, bei den andern sind die in ihnen eingeschlossenen Erythrozyten nicht mehr färbbar, und statt ihrer finden wir im Protoplasma braunrote Körnchen von Pigment; wiederum an anderen Stellen kleine lockere und poröse Häuflein eines schlecht färbbaren Protoplasmas; endlich gibt es solche, die Zellen vorstellen, welche mit Trümmern von roten Blutkörperchen in verschiedenem Maße ausgefüllt sind und mehr oder weniger große grünlichgelbe Tropfen Galle enthalten. In ihren Eigenschaften unterscheiden sie sich in keiner Beziehung von den in den Zellen der Leberbalken enthaltenen, nur daß die Tropfen von Galle in den Leberzellen gewöhnlich sehr klein und staubförmig sind.

Die meisten Erythrophagen befinden sich in den Kapillaren der peripherischen Teile der Leberläppehen: sie sitzen den Wänden der Kapillaren fest auf und scheinen mit den Leberzellen

1) Wir schlagen diese Benennung hiermit zum erstenmal vor, da sie unserer Meinung nach am treffendsten die Eigenschaft dieser Phagozyten kennzeichnet. 
ein Ganzes zu bilden, getrennt bloß durch eine dünne endotheliale Hülle. Der Grund, weshalb die Erythrophagen sofort nach ihrem Eintritt in die Leberkapillare an deren Wänden kleben bleiben, liegt in der Eigenschaft des Protoplasmas dieser Zellen. Am besten läßt sich diese Eigenschaft der Erythrophagen in isotonischen Lösungen ohne vorherige Bearbeitung derselben studieren. Zu diesem Zweck schaben wir vorsichtig mit dem Messer etwas von der frischen Schnittfläche der Leber ab und untersuchen den dabei erhaltenen Brei in einer physiologischen Lösung. Es ist dann nicht schwer, unter dem Mikroskop diese Erythrozytenfresser zu finden (Fig. 5, Taf. III).

Der Saft aus der Milz enthält in geeigneten Fällen ebenfalls eine große Anzahl von Erythrophagen, doch kommen sie hier nicht so leicht zum Vorschein, weil von der Schnittfläche der Milz zugleich mit ihnen eine große Anzahl anderer Formelemente des Blutes und der Pulpa abgestreift wird, so däß das Auffinden und nähere Studium der Eigenschaften der uns interessierenden Zellen erschwert ist.

In der physiologisehen Lösung erscheinen die Erythrophagen als große Elemente (bis $60 \mu$ im Durchmesser), haben ein sehr feinkörniges Protoplasma, dessen Menge abhängig ist von der Anzahl der gefressenen roten Blutkörperchen: je mehr ihrer in der Zelle, um so größer erscheint dieselbe und um so dünner ist der Protoplasmasaum, der in Form eines dünnen Ringes die Gruppen der Blutkörperchen umgibt. Gewöhnlich ist nur ein Kern vorhanden, der irgendwo an der Peripherie im etwas verdickten Protoplasma steckt; er ist bläschenförmig, recht groß, jedoch bei weitem nicht in allen Zellen deutlich zu unterscheiden. Wenn die Zahl der eingeschlossenen Blutkörperchen nicht groß ist, so ist auch die Zelle entsprechend klein und das Protoplasma stärker entwickelt. Die Form der Erythrophagen ist vielgestaltig: wenn die Zelle viele Erythrozyten enthält, ist sie sphärisch, was besonders schön im hängenden Tropfen zu sehen ist. Bei einem geringen Gehalt an roten Blutkörperchen, wie auch ganz ohne Einschluß derselben, erscheint die Zelle klein, von unregelmäßiger Form und oft gezackt. Solche Zellen sehen sehr den endothelialen und epithelialen Zellen ähnlich.

Diese Elemente sind wenig stabil und zerfallen selbst in indifferenten Lösungen: bereits einige Stunden, nachdem das Präparat angefertigt wurde, ist es schwer, die Erythrophagen in demselben aufzufinden: sie zerfallen leicht in einen feinen Detritus und sind nicht mehr erkennbar. Daher gelingt es nicht mit Hilfe des Abstrichverfahrens gute Dauerpräparate zu erhalten. Selbst die vorsichtigste Fixation vertragen die Erythrophagen nicht. Im getrockneten und gefärbten Präparate erscheinen sie als formlose Masse, in welcher mehr oder weniger veränderte Erythrozyten liegen und hier und da Kerne, die bald den Erythrophagen, bald den Leukozyten angehören.

Die Labilität des Protoplasmas dieser Zellen hat einen physiologischen Sinn: dadurch geschieht der Prozeß des Zerfalls und der Eliminierung der Erythrophagen in der Leber in kurzer Zeit, und es ist daher die Möglichkeit geboten, daß neue Erythrozytenträger aus der Milz in die Leberkapillaren gelangen können. Wenn sie nicht so schnell zerfallen würden, könnte sich leicht infolge der Verstopfung der Leberkapillaren durch die gestauten Massen eine Blutstase entwickeln; das finden wir jedoch nicht, selbst bei dem stärksten Zerfall von roten Blutkörperchen.

Zugleich zeichnet sich das Protoplasma dieser Zellen durch große Klebrigkeit aus. Man kann sich davon eine Vorstellung machen, wenn man das in einer isotonischen Lösung angefertigte Präparat unter dem Mikroskope betrachtet, wobei der Tubus des Mikroskops horizontal gesenkt ist, so daß das Präparat sich in vertikaler Stellung befindet. Wir sehen dann, daß die Erythrophagen unbeweglich bleiben, während die anderen frei in der Lösung schwimmenden Elemente (rote Blutkörperchen, Leberzellen, Leukozyten) infolge der Schwerkraft sich nach unten senken und aus dem Gesichtsfeld des Beobachters entschwinden. Diese Eigenschaft gab uns die Möglichkeit folgendes Mikrophotogramm (Fig. 5, Taf. III) zu bringen. Auf diesem Photogramm sind zwei Erythrophagen zu sehen, die mehrere rote Blutkörperchen enthalten; daneben liegen Leberzellen.

Die Erythrophagen besitzen also ein meistenteils voluminöses, lockeres, äußerst leicht zerfallendes klebriges Protoplasma. Ein rotes Blutkörperchen kann sich 
leicht in solch eine lockere Zelle einbohren, wozu durchaus nicht nötig ist, daß der Erythrozyt seine Elastizität verliert. ( $Q$ u i n e k e war der Ansicht, daß ein alternder, absterbender Erythrozyt seine Elastizität verliert.) Im Gegenteil, eben dank seiner vollkommenen Elastizität kann der Erythrozyt unter dem Druck des strömenden Blutes und infolge der fortwährenden Schläge von seiten der Formelemente desselben in den lockeren Protoplasmaknäuèl des Erythrophagen, der irgendwo an einer Gefäßwand sitzt, eindringen und sich festsetzen. Daher brauchen die Erythrophagen gar keine amöboiden Bewegungen zu besitzen; falls jedoch solehe vorhanden sind, können die Erythrozyten um so leichter yefressen werden.

Auf Grund dieser Überlegungen müssen wir annehmen, daß die Erythrophagen nicht die absterbenden roten Blutkörperchen, sondern die normalen fressen, $d . h$. iejenigen Formelemente des Blutes, die mit ihnen in Berührung kommen, denn wir können uns schwer vorstellen, wie die Erythrophagen die merkwürdige Eigenschaft besitzen sollten, aus vielen Milliarden roter Blutkörperchen bloß die absterbenden Exemplare auszusuchen. Wir finden freilich oft in den Phagozyten außer den völlig unveränderten roten Blutkörperchen noch zerfallende Körperchen, ihre Trümmer, Blutpigment und fremde Bestandteile. Jedoch widersprechen diese Tatsachen durchaus nicht unserer Anschauung, denn die Erythrozyten haben sich eben erst innerhalb der Zellen infolge der intrazellulären Verdauung zu Trümmern und Pigment verwandelt, während die fremden Bestandteile auf dieselbe Weise in die Zellen eingedrungen sind, wie die Formelemente, die mit den Phagozyten in Berührung gekommen sind. Ich bin daher der Ansicht, daß die Regeneration der roten Blutkörperchen bei Anämien, wie unter normalen Verhältnissen, sich derart vollzieht, daß ein bestimmter Teil der Formelemente des Blutes fortwährend von den Erythrophagen der Milz aufgefangen wird. Die letzteren Zellen zerfallen dann teils in der Milz selbst, zum größten Teil jedoch gelangen sie mit dem Blutstrom in die Leber, wo die günstigstenBedingungen für den Zerfall dieser Elemente und die Resorption der dabei entstehenden Produkte vorhanden sind. An Stelle der zugrunde gegangenen Elemente des Blutes schafft das Knochenmark neue und auf diese Weise wird binnen eines bestimmten Zeitraumes die gesamte Menge des Blutes erneuert. Der Unterschied bei normalen und pathologischen Zuständen ist bloß ein quantitativer. Denn, wenn auch das Knochenmark mit Leichtigkeit die normalen Verluste ersetzt, so erweist sich doch seine regenerative Fähigkeit ungenügend bei pathologisch erhöhtem Zerfáll der Erythrozyten, woraus dann eine quantitative Anämie resultiert. Da jedoch allmählich bei der beschleunigten Blutbildung unreife, schnell gefertigte Elemente, sog. Jugendformen, aus dem Knochenmark ins Blut übertreten, so entstehen auch qualitative Veränderungen des Blutes.

Des weiteren tritt der klebrige, voluminöse Erythrophag in die Kapillaren der Leber, wo der Blutstrom verlangsamt ist, klebt sofort an die Kapillarenwand in der Peripherie des Läppchens an und setzt sich daselbst fest. Auf diese Weise 
sind die günstigsten Bedingungen für den Zerfall und die Assimilation dieser Zellen und ihres Inhaltes gegeben.

Die Erscheinungen des Zerfalls der Erythrophagen können wir auf vorzügliche Weise illustrieren, indem wir vor der Färbung der Schnitte die mikrochemische Reaktion auf Eisen anstellen. (Das Präparat wird mit einer Lösung von Ferrozyankali getränkt und nachträglich mit Salzsäure behandelt.) Wir erhalten dann wunderschöne Bilder, an denen man alle Details der allmählichen Zerstörung der roten Blutkörperchen, die in den Leibern der Erythrophagen eingeschlossen sind, studieren kann,

An den Präparaten aus der Milz kann man sehen, daß die Mehrzahl der Erythrophagen unveränderte rote Blutkörperchen enthalten, deren Eisen sich noch in einer festen organischen Verbindung befindet, so daß weder die Körperchen selbst, noch die sie beherbergenden Zellen eine Färbung mit Berlinerblan zeigen. Mitunter sieht man eine Zelle, deren Leib leicht blau gefärbt ist, doch zeigen die Körnchen, die in ihr enthalten sind, keinerlei Reaktion auf Eisen. An anderen Stellen sehen wir Zellen, die bereits im Zerfall begriffene Blutkörperchen enthalten, denn sie sind blau gefärbt und in ihrem Leibe befinden sich bereits freie Häufchen von Hämosiderin. Solche Zellen befinden sich innerhalb der Sinus und Venen der Milz. In der Pulpa treffen wir ebenfalls Eisen an, doch ist es hier nur in geringen Mengen vorhanden und entspricht den. Stellen, wo die zerfallenden Erythrophagen zugrunde gegangen sind. An ihnen kann man weder den Kern, noch die in ihnen enthaltenen Erythrozyten deutlich sehen.

Im Stroma der Milz, desgleichen um die Gefäße herum, namentlich in den perivaskulären, lymphatischen Räumen der Arterien der Malpigh ischen Körperchen, trifft man Ablagerungen von einzelnen Körnchen von Berlinerblau, mitunter auch kleine Anhäufungen desselben. Jedoch ist im allgemeinen in der Milz wenig Hämosiderin vorhanden. Anders ist es in der Leber: das Präparat, das in Salzsäure gelegen hatte und daraufhin mit einer Lösung von Ferrozyankali behandelt wurde, beginnt nach einigen Minuten schnell blau zu werden, als ob es mit einer Lösung von $L$ öfflers Methylenblau gefärbt wäre; die Leber erweist sich als sehr eisenhaltig.

Bei der mikroskopischen Untersuchung der nach diesen Verfahren behandelten Präparate aus der Leber finden wir große Ablagerungen von Eisen in den Erythrophagen selbst, wie auch in den Leberzellen (s. Taf. III, Fig. 6), teilweise in den Endothelien der Kapillaren und um die interlobulären Gefäße im Bindegewebe. In den Leberzellen erscheinen diese Eisenablagerungen in Form von kleinen Körnchen, die bald überall gleichmäBig, bald als Häufchen an einem Ende der Zelle oder um den Kern herum verteilt sind. Die einen Zellen enthalten mehr Eisen, die andern weniger, jedoch überall mehr oder weniger gleichmäßig. Ganz andere Verhältnisse finden wir bei den Erythrophagen. In den Kapillaren fällt uns vor allen Dingen die Größe der blauen Partien auf, die den Zellen entsprechen, welche die roten Blutkörperchen enthalten. Je schärfer sie hervortraten, um so weniger Eisen enthalten sie und um so besser ist der Kern der Erythrophagen gefärbt. Andrerseits finden wir Exemplare, in denen weder der Kern, noch die Erythrozyten zu unterscheiden sind, und die Zelle ein Häuflein von großen Eisenklümpehen vorstellt, die in einer dünnen bläulichen Hülle eingeschlossen sind; mitunter ist auch die Hülle nicht zu sehen. Zwischen diesen Extremen gibt es eine Menge Übergänge, aus welchen man sich klar vorstellen kann, mit welcher Gleichmäßigkeit der ZerstörungsprozeB der roten Blutkörperchen und der sie einschließenden Zelle stattfindet, ein Auflösungsprozeß und völliger Zerfall, wenn an Stelle der Zelle bloß ein durchlöchertes Gerippe, das schwach grau gefärbt ist, oder kleine Detrituskörnchen oder die feinsten Eisenpartikelchen nachbleiben.

Das Eisen sammelt sich hauptsächlich in den peripherischen Teilen der Leberläppchen und seine Anwesenheit in großen Mengen an diesen Stellen beweist, daß eben hier der hauptsächliche Untergang der roten Blutkörperchen statt- 
findet. Dieses Faktum ist von ganz besonderem Interesse, denn es beweist nur auf das überzeugendste, daß bei dem massenhaften Untergang der Erythrophagen in den peripherischenTeilen der Leberläppchen eben an diesen Stellen die Zerstörungsprodukte der roten Blutkörperchen in großer Menge frei werden. Die Anhäufung dieser Produkte muß mit Notwendigkeit einen Reiz in der Peripherie der Läppchen ausüben, um so stärker, je mehr der Prozeß ausgeprägt ist und, falls er lange anhält, irritative Entzündungserscheinungen im interlobulären Bindegewebe hervorrufen; mit anderen Worten, der verstärkte Zerfall der Erythrozyten in den peripherischen Teilen der Leber: läppchen, der durch die Erythrophagen vermittelt wird, löst die entzündlichen Bindegewebswucherungen im in terlobulären Gewebe a us. So einfach läßt sich die Entwicklung der Leberzirrhosen erklären.

Falls wir uns nun zu unserem Ausgangsfall wenden, so finden wir auch wirklich besonders an den Rändern der Leber und deren linkem Lappen eine stark entwickelte ringförmige Zirrhose. B a n t i sagt auch, daß die Leberzirrhose bei der Milzanämie nicht am Anfang der Krankheit, sondern erst in der dritten, letzten Periode derselben eintritt. Es gehen diesem Zustand die Erscheinungen der Blutanämie und die Splenomegalie voraus. B a n t i nimmt an, dab die Ursache der Krankheit in der Milz zu suchen ist, und schlägt ihre Entfernung vor. Und wirklich tritt auch oft nach der Exstirpation der Milz Heilung ein, während die nicht operierten Fälle zugrunde gehen.

M a r a g l i a n o hat unter 11. operierten Fällen bei der B a n t i schen Krankheit 9 Heilungen erzielt. $\mathrm{J}_{\mathrm{o}} \mathrm{r}$ d a n unter 17 operierten Fällen 14 Heilungen; $\mathrm{Bessel-Hage} \mathrm{n,} \mathrm{Harris} \mathrm{und} \mathrm{Her} \mathrm{zog} \mathrm{(die} \mathrm{Autoren} \mathrm{sind} \mathrm{nach} \mathrm{F.} \mathrm{Kl} \mathrm{o} \mathrm{p} \mathrm{-}$ $s t o \mathrm{ck}^{3}$ zitiert) berichten ebenfalls über Heilerfolge nach der Milzexstirpation,

$\mathrm{Klopst} \mathrm{ock} \mathrm{(S.} \mathrm{114)} \mathrm{ist} \mathrm{auf} \mathrm{Grund} \mathrm{dieser} \mathrm{Tatsachen} \mathrm{zugleich} \mathrm{mit} \mathrm{B} \mathrm{a} \mathrm{n} \mathrm{t} \mathrm{i}$ der Anschauung: ,der Milztumor erscheint hier nicht nur als Begleiterscheinung, sondern ist von wesentlichster Bedeutung für das ganze Krankheitsbild".

Unsere Untersuchungen haben auch gezeigt, daß in der Milz in sehr großer Zahl Zellen auftreten, die die roten Blutkörperchen phagozytieren. Bei der Splenektomie wird folglich ein Herd entfernt, in welchem die Zerstörung der roten Blutkörperchen stattfindet. Nach der Entfernung der Milz treffen wir keine Erythrophagen mehr in der Leber an und wir finden daher auch keinerlei Zerfallsprodukte derselben; die Erscheinungen der Zirrhose klingen allmählich ab oder es kommt überhaupt nicht zu der Entwicklung einer solchen.

Die Erscheinungen der Reifung des Bindegewebes in der Leber, hervorgerufen durch den erhöhten Zerfall der roten Blutkörperchen, der schließlich zu zirrhotischen Veränderungen führt, müssen natürlicherweise auch in der Milz stattfinden. Der Grund der Reizung des Gewebes der Pulpa muß abhängig sein von der Zahl der in der Milz zerfallenden roten Blutkörperchen (resp. der zerfallenden Erythrophagen): je stärker dieser Prozeß ausgesprochen ist, um so früher und 
stärker müssen auch die zirrhotischen Veränderungen in der Milzpulpa wahrzunehmen sein. In unserem Fall von B a n t ischer Krankheit hing der Milztumor, der von sehr fester Konsistenz war, hauptsächlich von der reichlichen Entwicklung und Verdickung des Stromas der Milzpulpa ab. In der Literatur sind Fälle beschrieben, wo die Splenomegalie noch stärker entwickelt war: die Milz erreicht mitunter das Gewicht von $1200 \mathrm{~g}$ und noch mehr. ( Z i e gle r ${ }^{4}$ ). Die Malpigh i schen Knäuelchen weisen einige Veränderungen auf, die darin bestehen, daß um die Arterien herum eine Verdickung der Bindegewebshaut auftritt, während. zwischen den lymphoiden Elementen einiger M alpig h i schen Körperchen, namentlich in den zentralen Partien, indirekte Teilungsfiguren der Kerne zu sehen sind - also Erscheinungen der Proliferation. In den peripherischen Teilen sieht man mitunter größere Zellen, die sich in keiner Weise von den Erythrophagen unterscheiden und von denen einige rote Blutkörperchen in sich eingeschlossen haben. Eisen findet man nur um die Arterien herum.

Unsere Untersuchungen haben also erwiesen, daß in unserem Fall von B a n t i scher Krankheit die während des Lebens wahrgenommene Anämie hervorgerufen wurde durch die erhöhte Aufnahme der roten Blutkörperchen von bestimmten Zellen der Milz, in welchen sie zum Teil zerfallen, während der größte Teil in die Leber gelangt, wo sie dann endgültig zugrunde gehen. Die Zerfallsprodukte werden dann teils von den Leberzellen aufgesogen, teils gelangen sie mit dem Blut in die Blutbahn. Ein großer Teil dieser Zerfallsprodukte der Erythrozyten ruft in den entsprechenden Organen Reizerscheinungen hervor mit konsekutiver entzündlicher Wucherung des Bindegewebes. Dieser Prozeß führt dann zu einer Vergrößerung der Milz (Fibroadenie nach B a n ti) und zu einer Leberzirrhose. Das Knochenmark wird zur verstärkten Tätigkeit erweckt, wird rot, lymphoid und beginnt in erhöhtem Maße die in Massen zugrunde gehenden Erythrozyten zu ersetzen, jedoch erweist es sich der enormen Anforderung weder in quantitativer (quantitative Anämie), noch in qualitativer Hinsicht gewachsen. Es treten im Blut Jugendformen: Polychromatophile, kernhaltige Erythrozytenformen mit ungenügendem Gehalt an Hämoglobin, wie auch Krüppelformen der Erythrozyten, Makro-, Mikro- und teilweise auch Poikilozyten auf. Es mangelt dem Organismus. auch tatsächlich an dem nötigen Hämoglobin zur Bildung von normalen Erythrozyten, da ein großer Teil derselben den Körper mit der Galle verläßt: es tritt eine sogenannte Pleiochromia ein, die zu einer verstärkten Bildung von Galle in der Leberpolycholie führt, wie das $\mathrm{N}$ a u n y $\mathrm{n}, \mathrm{S}$ t a d e $\mathrm{lm}$ a $\mathrm{n} n, \mathrm{M}$. J. A f a $n$ a s s jew u. a. gezeigt haben. Zugleich ruft die erhöhte Aufnahme der Zerfallsprodukte der roten Blutkörperchen, die doch pyrogene Stoffe enthalten, eine beständige, wenn auch nicht gleichmäßige Erhöhung der Temperatur hervor und führt schließlich zu einer Intoxikation mit Fermenten, die in den roten Blutkörperchen enthalten sind ( $\mathrm{Sil}$ b e r man $\mathrm{n}^{5}$ ).

Mit dem erhöhten Zerfall der roten Blutkörperchen stimmt auch das Auftreten des sog. ,hämatogenen“ Ikterus überein. In den Zelleibern vieler Ery- 
throphagen, die wir bei der B a n t i schen Anämie in der Leber antreffen, befinden sich, wie wir gesehen haben, außer den roten Blutkörperchen und ihren Zerfallsprodukten auch noch Tröpfchen von Galle. Das letztere ist für uns von der größten Bedeutung, denn es erklärt uns, auf welche Weise bei dem massenhaften Zerfall von roten Blutkörperchen ein Ikterus auftreten kann.

Die Galle kann nicht ohne Hilfe der Leberzellen gebildet werden. $Q$ u i n c k e und dessen Schüler haben die feststehende Tatsache erwiesen, daß es im menschlichen Körper keine andere Stelle und andersartige Zellen gibt, in welchen Galle gebildet werden kann, daß sie folglich einzig als Produkt der Tätigkeit der Leberzellen anzusehen ist. Wenn wir also in den Erythrophagen der Leber Galle nachweisen (die Erythrophagen der Milz enthalten nie Galle), so ist das so zu verstehen, daB sie dieselbe keineswegs selbst gebildet, sondern von den Leberzellen erhalten haben. Die Galle gelangt auf folgende einfache Weise in den Zellenleib der Erythrophagen. Der Erythrophag setzt sich infolge seiner Klebefähigkeit an der Wand der Leberkapillare fest und ist von der Leberzelle bloß durch eine dünne endotheliale Membran getrennt. Es sind also günstige Bedingungen für eine Osmose geschaffen: die Zerfallsprodukte der Erythrozyten treten aus dem Protoplasma der sie beherbergenden Zelle infolge der Endosmose in die Leberzelle, wo sie in Galle umgewandelt werden. Falls das gelieferte Material groß war, so wird auch die Menge der gebildeten Galle eine große sein. Wo wir aber Vorgänge der Endosmose haben, da muß auch eine Exosmose stattfinden: die Galle, die in den Leberzellen gebildet wurde, muß notwendigerweise teilweise in die Zellenleiber der Erythrophagen gelangen, ja es wäre sonderbar, wenn solches nicht stattfinden würde. Des weiteren müssen infolge der fortwährenden osmotischen Prozesse die Erythrophagen schließlich zerfallen, das in ihnen enthaltene Tröpfchen Galle wird frei und tritt notgedrungen ins Blut. Falls es viele derartige Tröpfchen gibt, tritt schließlich eine Gelbfärbung der Haut auf - Ikterus.

Die Art, wie wir uns das Zustandekommen des Ikterus bei der erhöhten Zerstörung der roten Blutkörperchen durch die Erythrophagen erklären, stellt durchaus keine neue $\mathrm{T}$ h e o r i e vor, sondern ist bloB eine richtig verstandene und erklärte, mit dem Auge wahrnehmbare $\mathrm{T}$ a $\mathrm{ts}$ a $\mathrm{ch}$ e, die keinem Zweifel unterliegt.

In unserem Fall von B a n t i scher Krankheit hatten wir auch einen Ikterus, der freilich nicht stark ausgesprochen war, aber doch zweifellos seit längerer Zeit bestand. Daß wir es in diesem Fall nicht mit einem Stauungsikterus zu tun haben, ist aus dem Sektionsbericht zu ersehen: die galleabführenden Wege waren völlig unverändert und die Ausmündungsstelle des Choledochus in dem Duodenum frei.

Auf diese Weise wird uns der gesamte Symptomenkomplex der B a n t i schen Anämie genügend verständlich; unaufgeklärt bleibt bloß die Grundursache, welche die Vermehrung und verstärkte Tätigkeit der Erythrophagen hervorruft. Jedoch darauf kommen wir später zurück.

Die Tatsache der Vernichtung der einen Zelle des Körpers durch die andere tritt in unserem Fall so deutlich hervor, daß sich unwillkürlich die Frage aufdrängt, 
ob die beschriebenen Erscheinungen bloB in diesem einen Falle stattfinden und ob nicht etwas Analoges unter normalen und anderen pathologischen Zuständen vorkommt.

Vor allen Dingen interessiert uns die Frage, auf welche Weise die Regeneration des Blutes unter normalen Verhältnissen stattfindet.

Die nähere Untersuchung unseres Falles hat uns gelehrt, daß der Prozeß des Untergangs der Erythrozyten bei der B anti schen Krankheit bedeutend verstärkt ist und daß ein ähnlicher Zustand auch beim gesunden Mensehen vorkommt, nur daß er hier durch einen langsamen Verlauf gekennzeichnet ist, bei welchem der Verlust an roten Blutkörperchen, die von den Erythrophagen vernichtet werden, in vollem Maße ersetzt wird durch die beständige, wenn auch wenig intensive Tätigkeit der blutbildenden Organe.

Wenn wir uns nun zur Untersuchung von normalen Organen, in denen der Zerfall der roten Blutkörperchen und die Resorption der dabei entstehenden Zerfallsprodukte stattfindet, wenden wollen, d. h. also zur Milz und zur Leber, so müssen wir vor allen Dingen die Tatsache hervorheben, daß alle Histologen ohne Ausnahme in der Milzpulpa sowie in den Blutgefäßen derselben große Zellen beschreiben, die von den meisten Autoren als $\mathrm{Milzzellen}$ benannt werden und in ihrem Inneren rote Blutkörperchen und deren Trümmer enthalten. Man braucht durchaus nicht professioneller Histologe zu sein, um diese Zellen in jeder Milz mit Leichtigkeit aufzufinden, man muB sie nur aufmerksam aufsuchen, besonders in Präparaten, die nicht in Formalin, sondern in einer anderen Flüssigkeit fixiert sind. Wir treffen freilich diese Zellen unter normalen Verhältnissen seltener an, jedoch sind stets auf der Fläche eines einzigen mikroskopischen Präparates mindestens ein Dutzend aufzufinden. Diese Zellen sind die oben beschriebenen Erythrophagen: sie fangen die roten Blutkörperchen auf, verarbeiten sie dann entweder in der Milz selbst (in jeder Milz läßt sich Hämosiderin nachweisen), oder schaffen sie mit dem Blutstrom in die Leber, wo sie einer endgültigen Zerstörung anheimfallen und dann das Material zur Bildung von Galle liefern.

Diese Zellen befinden sich auch in der normalen Leber. $Q \mathbf{u}$ in $\mathbf{c k}$ e beschreibt weiße Blutkörperchen, die in den Leberkapillaren die roten Blutkörperchen verschlingen, doch sind das natürlich keine Leukozyten, sondern dieselben Erythrophagen, die in die Leber aus der Milz gelangt sind. Auch in der Leber können wir immer die Erythrophagen nachweisen, wenn wir nur genügend aufmerksam untersuchen. Es kann das dadurch erleichtert werden, daß wir vor der Färbung der Präparate die Reaktion auf Eisen anstellen: die blauen Punkte in den Kapillaren lenken sofort unsere Aufmerksamkeit auf diese wunderbaren Zellen.

Die Zerstörung der roten Blutkörperchen geschieht also auch unter normalen Verhältnissen hauptsächlich mit Hilfe dieser Erythrophagen, welche die Elemente des Blutes in der Milz auffangen, in ihren Zelleibern verdauen, teils in der Milz selbst zerfallen, zum größten Teil jedoch mit dem Blutstrom in die Leber gelangen, sich an den Wänden der peripherisehen Partien der Blutkapillaren festsetzen und auf diese Weise die roten Blutkörperchen in der Leber zurückhalten. Ohne eine derartige Zurückhaltung der roten Blutkörperchen könnten wir uns unmöglich vorstellen, wie sie von den Leberzellen selbst, eine beständige, starke Verlangsamung der Blutzirkulation vorausgesetzt; aufgesogen werden könnten.

Auf diese Weise pflegt der Zerfall der roten Blutkörperchen in normalen Fällen vorzugehen und wie wir bereits früher auseinandergesetzt haben, brauchen 
wir vom rein physikalischen Standpunkte aus keineswegs anzunehmen, daß blob die absterbenden Elemente dem Zerfall anheimfallen.

Den Ersatz für die normalen und auch pathologisehen Verluste schafft beim Erwachsenen das Knochenmark, nur ist im ersten Fall seine Funktion nicht erhöht, daher auch das Knochenmark keinen lymphoiden Charakter annimmt.

Wir konnten also auf Grund unserer Untersuchungen bei der B a n $\mathrm{t}$ i schen Krankheit einen Einblick gewinnen in den zurzeit noch dunklen Mechanismus der Zerstörung der roten Blutkörperchen bei normalen Zuständen und bei primären Anämien.

Das Verdienst $\mathrm{B}$ a $\mathrm{n} \mathrm{t}$ i s besteht eben darin, daß er zuerst den klinischen Zusammenhang zwischen Anämie, Splenomegalie und Leberzirrhose nachgewiesen hat. Wir sind der Meinung, daß es uns gelungen ist, zwischen diesen drei klinischen Erscheinungsformen der Krankheit auch einen physiologischen Zusammenhang zu finden. Es entsteht ursprünglich in der Milz, infolge bestimmter Bedingungen, eine erhöhte Zerstörung der roten Blutkörperchen durch besondere Zellen, so daß eine Anämie sich schließlich entwickelt. Der Prozeß des verstärkten Zerfalls dieser Zellen samt ihrem Inhalt ruft eine Splenomegalie und die Ablagerung von großen Mengen Eisen mit konsekutiver Bildung einer Leberzirrhose hervor; in einigen Fällen tritt dabei auch ein Ikterus auf. Das Knochenmark verwandelt sich aus dem gelben in rotes, Iymphoides und ersetzt nach Möglichkeit den erhöhten Verlust an roten Blutkörperchen.

Dieser enge Zusammenhang zwischen den Erscheinungen der Anämie und der Leberzirrhose bei der B a n t i schen Krankheit erweckt in uns natürlicherweise die Frage, ob nicht auch die anderen Leberzirrhosen infolge eines erhöhten Zerfalls der roten Blutkörperchen entstehen?

Aus der Pathologie wissen wir, welch große Ablagerungen von Eisen (Hämosiderosis) bei der zirrhotischen Leber ( $\mathrm{Z} \mathrm{i} \mathrm{e} \mathrm{g} \mathrm{l} \mathrm{e} \mathrm{r} \mathrm{a.} \mathrm{a.} \mathrm{O.)} \mathrm{hauptsächlich} \mathrm{in} \mathrm{den}$ peripherischen Partien der Läppehen gefunden werden.

Zi e gl e r (S. 688) weist auch darauf hin, daß diese Krankheit im engen Zusammenhang mit dem erhöhten Zerfall der roten Blutkörperchen steht. Andrerseits haben Rosenste in ${ }^{6}$ und $W l$ a y e ${ }^{7}$ gefunden, da $\beta$ bei Leberzirrhose die Zahl der roten Blutkörperchen herabgesetzt ist. In einem Falle von Zirrhose mit stark entwickeltem Aszites fanden wir 4800000 rote Blutkörperchen und den Hämoglobingehalt gleich $50 \%$. Im Blute waren unvollkommene Erythrozytenformen vorhanden: zyanophile, schwach gefärbte Körperchen, Mikro- und Makrozyten und wenig zahlreiche Poikilozyten. Die geringe Verminderung der roten Blutkörperchen trotz des herabgesetzten Gehalts an Hämoglobin kann seine Erklärung in der Verdickung des Blutes infolge des starken Aszites finden. Gra w i $z^{8}$ ) berichtet über einen Fall von Leberzirrhose, wo nach der Punktion infolge der Erleichterung der Blutzirkulation und entsprechender Verdünnung des Blutes die Zahl der roten Blutkörperehen geringer wurde.

Das Knochenmark verwandelt sich nach Bleichroeder ${ }^{9}$ ) bei Leber- 
zirrhosen und bei Anämien in rotes, d. h. es geht aus dem ruhenden Zustande in einen aktiven über. Als sehr charakteristisch erweisen sich die Veränderungen in der Milz bei verschiedenen Leberzirrhosen; die Splenomegalie ist die beständige Gefährtin der Zirrhosen. Die Veränderungen in der Milz sind sehr charakteristisch und durchaus nicht abhängig von einer etwaigen Blutstauung.

Der Unterschied zwischen der Staungsmilz und der zirrhotischen besteht im folgenden: Die Stauungsmilz ist sehr derb, kirschrot und hat deutlich entwickelte Trabekel; die Pulpa läßt sich nicht abstreifen, das Organ ist wenig vergrößert, oft sogar verkleinert, atrophisch. Im Gegensatz dazu ist die zirrhotische Milz meistenteils groß, mitunter auch sehr groß, die Pulpa weich, hellrot, läßt sich leicht von der Schnittfläche abschaben; sie ist hyperplasiert. Die mikroskopische Untersuchung ( B l e i c h r o e d e r a. a. O. S. 447) zeigt uns, daß die Stauungsmilz durch ihren beständigen Reichtum an Blut ausgezeichnet ist, während bei Zirrhosen die Pulpa oft verhältnismäBig blutarm ist. Im Vergleich mit der Stauungsmilz enthält die zirrhotische Milz bedeutend mehr Pigment, das die Reaktion auf Eisen gibt, woraus folgt, daß in der Milz bei den Leberzirrhosen ein beträchtlicher Zerfall der roten Blutkörperchen stattfindet. Nach Bleich roeders Untersuchungen befinden sich auch in der zirrhotischen Milz, im Gegensatz zu der Stauungsmilz, viele große Zellen, welche mit Triazid eine homogene, dunkelrote Farbe annehmen. Ähnliche Zellen fand dieser Autor auch in normaler Milz, besonders oft aber in der Milz bei Typhus abdominalis und anderen Infektionskrankheiten. Diese Zellen liegen teils in der Pulpa, hauptsächlich jedoch in den Venen und Blutsinus der Milz; mitunter sammeln sie sich in solch großer Menge an, daß sie an "sarkomatöse Wucherungen der Milzzellen" erinnern. Leider gibt uns der Autor keine genaue Beschreibung des Protoplasmas der uns interessierenden Zellen, erwähnt nichts von Einschließungen in ihnen, jedoch identifiziert er sie mit Zellen, die B or is s o w a ${ }^{\mathbf{1 0}}$ beschrieben hat, welche ähnliche Zellen in großer Anzahl bei der Bantischen Krankheit und in zwei Fällen von Splenomegalie fand, wobei sie in ihren Zelleibern oft rote Bhtkörperchen oder ihre Trümmer entdeckte.

Wir besitzen derartige Präparate von der Milz bei Leberzirrhosen leider nicht in unserer Kollektion und sind daher nicht imstande, selbst einen weiteren Beleg dafür zu erbringen, daß bei dieser Krankheit in der Milz Erythrophagen angetroffen werden. Auf Grund der Literaturangaben jedoch sind wir überzeugt, daß sie sich daselbst entwickeln. Wir finden sie auch fast in allen unseren alten Präparaten von Leberzirrhose, während doch die Erythrophagen, wie wir oben gezeigt haben, nur aus der Milz in die Leber kommen können. Das histologische Bild bei der Leberzirrhose entspricht vollkommen dem von uns bei der $\mathrm{B}$ antischen Krankheit beschriebenen, wobei die Erythrophagen bei den atrophischen wie auch hypertrophischen Lebërzirrhosen gefunden werden.

B lei chroeder hält die geschilderten Veränderungen in der Milz nicht bloß für die zirrhotische Milz charakteristisch, sondern er fand regelmäßig ähnliche Bilder in der Milz bei den Anämien, namentlich den perniziösen, und stellt daher folgenden Satz auf (Seite 448): „Die Milz bei Leberzirrhose weist also eine gewisse Ähnlichkeit mit der Milz bei Blutkrankheiten auf.

Es bestehen also bei der Leberzirrhose alle diejenigen Symptome, die für die B a $\mathrm{n}$ i sche Krankheit charakteristisch sind, und zwar:

1. Anämie (quantitative und qualitative),

2. Splenomegalie, die der Leberzirrhose vorausgeht, 
3. Entwicklung von Bindegewebe in der Leber,

4. rotes Knochenmark.

Die mikroskopischen Veränderungen in der Milz und in der Leber sind, wie wir gesehen haben, bei beiden Krankheitsformen die gleichen. Und auch klinisch ist der Untersehied zwischen beiden Erkrankungen, wenn wir die einzelnen Symptome genau analysieren, ein bloß quantitativer. Während bei der Bantischen Krankheit die Leberzirrhose erst im Endstadium der Krankheit auftritt, prävalieren bei den eigentlichen Leberzirrhosen die pathologisch-anatomischen Veränderungen in der Leber bereits sehr früh über alle anderen. Wir müssen daher annehmen, daß die Ursache und das Wesen beider Krankheiten identisch sein müssen. Die Bantische Anämie wie auch die zirrhotische sind das Resultat der erhöhten Tätigkeit der Erythrophagen in der Milz, die die roten Blutkörperchen in großen Mengen zerstören. Der Untergang der Erythrophagen in der Milz ruft eine Vergrößerung des Organs hervor, und ihr massenhafter Zerfall in der Leber, hauptsächlich in den peripherischen Teilen der Leberläppchen, führt zu einer Reizung und entzündlichen Wucherung in der Gliss onschen Kapsel. Das Auf treten des Ikterus, der jedoch nicht obligatorisch ist, findet seine Erklärung, wie wir bereits früher auseinandergesetzt haben, in dem in den Leberkapillaren stattfindenden Zerfall der Erythrophagen, die von den Leberzellen Gallentröpfchen erhalten haben. Das rote Knochenmark wandelt sich in gelbes um, um den Verlust der massenhaft zugrunde gegangenen Erythrozyten zu ersetzen.

Die Zirrhosen der Leber sind folglich der Ausdruck für die Anämie, und die Veränderungen in den Organen bei den Zirrhosen sind identisch mit den Erscheinungen, die wir bei den primären Anämien antreffen.

Wir können auch die umgekehrte Schlußfolgerung machen: Jede pri märe Anämie, diedureh eine verstärkte Zerstörungder roten Blutkörperchendurch die Erythrophagen bedingt ist, kannzu einer Leberzirrhoseführen, falls in der Leber während eines längeren Zeitraumes eine massenhafte Zerstörung der Erythrozyten stattgefunden hat.

Auf Grund dieser Utberlegung können wir auch die logisehe Folgerung machen, dab bei denjenigen Krankheiten, bei denen sich eine A $n \ddot{a} \mathrm{mi}$ e und mitunter auch Leberzirrhose entwickeln, notgedrungen auch eine Erythrophagiestattfinden muB, d. h. eine erhöhte Zerstörung der roten Blutkörperchen durch besondere Zellen der Milz und deren Zerfall in den Leberkapillaren.

$\mathrm{Zu}$ solchen Krankheiten gehören z. B. die Tuberkulose und die Syphilis. Es ist bekannt, daß bei der Tuberkulose, in allen Stadien derselben ( $\mathrm{Gr}$ a w it z a. a. O.), und bei den Erscheinungen der Syphilis ( S ele ne w ${ }^{11}$ ) sich beständig eine Anämie entwickelt. Anderseits ist auch allgemein bekannt, daß die Leber bei der Syphilis sehr oft Veränderungen aufweist und daß es oft zur Entwicklung einer syphilitischen Zirrhose kommt. Bartel und $\mathrm{Ne}$ u $\mathrm{m}$ a $\mathrm{n} \mathbf{n}{ }^{12}$ fanden bei 
ihren Untersuchungen über den Einfluß, den der lymphatische Apparat auf die Virulenz der Tuberkelbazillen ausübt, daß in den Fällen, wo es gelingt, die Virulenz der Tuberkelbazillen herabzusetzen, eine allgemeine Tuberkulose bei den Tieren nicht eintrat, während in der Leber, an Stelle des $t u b e r k u$ lösen Prozesses, zirrhotische Veränderungen auftraten. Die Untersuchungen wurden mehrfach wiederholt und bestätigt. Mo u is s e t und $\mathrm{B}$ o n $\mathrm{n} \mathrm{a} \mathrm{m} \mathrm{o} \mathrm{rr}^{13}$ fanden ebenfalls Beziehungen zwischen den tuberkulösen Veränderungen versehiedener Organe und der Entwieklung einer Leberzirrhose. Ich selbst habe während meiner zwanzigjährigen pathologiseh-anatomischen Tätigkeit mehrere Tausend Sektionen ausgeführt und kann behaupten, daß sehr oft bei der Tuberkulose in den Sektionsprotokollen ein Knirschen beim Durchschneiden der Leber oder eine deutlich entwickelte Leberzirrhose notiert wurde. Jedes Sektionsprotokollbuch wird diese Tatsache bestätigen. Und es ist auch merkwürdig, daß in jedem Falle von Tuberkulose die Milz verändert ist: sie ist immer mehr oder weniger vergrößert, ihre Pulpa ist meistenteils hyperplasiert (läßt sich leicht mit dem Messer von der Schnittfäche abstreifen), mitunter ist sogar eine deutliche Splenomegalie vorhanden.

Bei der Tuberkulose und der Syphilis haben wir es also mit einer Anämie und nicht selten auch mit zirrhotischen Veränderungen in der Leber zu tun, während die Milz mehr oder weniger vergrößert ist. Wir haben folglich das Recht, bei diesen Krankheiten eine erhöhte Erythrophagie vorauszusetzen.

Und wirklich fanden wir auch bei der ersten Sektion in einem Fall von ulzeröser Lungentuberkulose bei einem jungen, noch nicht kachektischen Individuum, daß die Wirklichkeit unsere Erwartungen übertraf. Die mikrophotographischen Aufnahmen (s. Taf. IV, Fig. 7 u. 8) von Präparaten aus der Milz und Leber illustrieren das am deutlichsten: hier ist der Vorgang der Vernichtung der roten Blutkörperchen in der Milz und der Reichtum der Leber an Erythrophagen noch stärker entwickelt, als in unserem Fall von B a n t i scher Krankheit. Das Knochenmark war rot, hyperplasiert und zeigte aufs deutlichste den großen Verlust des Körpers an roten Blutkörperchen.

Der nächstfolgende zweite Fall von. Tuberkulose, der einen galoppierenden Verlauf nahm, zeigte uns dieselben Erscheinungen in der Milz und Leber, bloß mit einem recht merkwürdigen Unterschied. In der ums doppelte vergrößerten Milz und in der Leber fanden sich miliare Tuberkel mit zum größten Teil nekrotischen Veränderungen ohne Riesenzellen. Die Tuberkel waren so klein, daß sie nur unter dem Mikroskop gesehen werden konnten. Es stellte sich nun heraus, daß fast alle Milztnberkel von Zellen, vollgepfropft mit roten Blutkörperchen, umgeben waren. Die Erythrophagen bildeten einen fast geschlossenen mehrreihigen Kreis und schienen auf diese Weise das gesunde Gewebe vor dem tuberkulösen Herde zu schützen.

Die Erythrophagen erweisen sich also als echte Phagozyten im Sinne von Mets chnikow. Sie besitzen die Fähigkeit, außer den roten Blutkörperchen noch andere körperfremde Bestandteile aufzusaugen, wie Tusche, Karmin, Kohlepartikelchen, Pigmentkörnchen, Malariaplasmodien, Tuberkelbazillen, die blassen Spirochäten u. a. m., sie nehmen den Kampf mit der Infektion auf und vermehren sich infolge des Reizes der Gifte auf diejenigen Elemente des Körpers, aus denen diese Phagozyten gebildet werden - also aus den Malpighischen Körperchen der Milz und den Lymphknötchen. Da also diese merkwürdigen Zellen die Fähig- 
keit besitzen, alle frei in den Gewebssäften schwimmenden Elemente, die mit ihnen in Berührung kommen, aufzufangen, so sind es vor allem die Formelemente des Blutes - die roten und weißen Blutkörperchen, die sie fressen. Es scheint, daß in einigen Erythrophagen auch Tuberkelbazillen nachgewiesen werden können, wie denn auch $\mathrm{Nik}$ if or of $\mathrm{f}^{\mathbf{1 4}}$ in ihnen die Spirochäten des Rückfalltyphus nachgewiesen hat. Wir hatten übrigens noch nicht genügend Zeit, um die näheren Erscheinungen der phagozytären Wirkung der Erythrophagen bei den Infektionskrankheiten zu studieren; wir möchten hier nur bemerken, daß die Anämie und deren Folgezustände bei Tuberkulösen das Resultat einer indirekten, vielleicht auch für den Organismus schädlichen Tätigkeit der Phagozyten vorstellt, bei welchem auch die roten Blutkörperchen gefressen werden, da sie eben als „Phagozyten ohne Auswahl" wirken. Es ist das die notwendige Folge der Erscheinung, daß der Organismus unter dem Einfluß des tuberkulösen Giftes zum Selbstschutz Elemente mobilisiert, die das Virus unschädlich machen sollen, entweder durch direktes Aufsaugen derselben oder mit Hilfe von extrazellulären Stoffen - den Antitoxinen.

Um die Tuberkel in der Leber herum werden wir selbstverständlich eine solche ringförmige Ansammlung der Erythrophagen nicht antreffen, denn hier befinden sich die mitBlutkörperchen gefüllten Zellen in den Leberkapillaren, sitzen den Wänden fest auf und können nicht mehr ihre phagozytäre Wirkung entfalten; sie zerfallen auch sehr schnell samt ihrem Inhalt (vielleicht auch mit den Infektionserregern den Tuberkelbazillen, den blassen Spirochäten u. a.), da sie dem starken Einfluß des Lebersaftes ausgesetzt sind.

Infolge unseres Mangels an Leichenmaterial gelang es uns nicht nachzuweisen, daß auch die Anämie bei der Syphilis durch eine erhöhte Erythrophagie in der Milz bedingt wird. Jedoch in mikroskopischen Präparaten von syphilitischen Leberzirrhosen sahen wir einen solehen Reichtum an Erythrophagen, besonders in den peripherischen Partien der Leberkapillaren, der genau demjenigen bei Tuberkulose und andern Leberzirrhosen entsprach, so daß wir daraus wiederum auf die erhöhte Tätigkeit der Erythrophagen auch in der Milz der Syphilitiker schließen können. Wir dürfen jedoch nicht außer acht lassen, daß es auch Fälle geben kann, wo wir bei Anämien, die durch Erkrankungen der Milz hervorgerufen worden sind, bei Tuberkulose und bei Leberzirrhosen, in den mikroskopisehen Präparaten keinerlei Erscheinungen einer Phagozytose der roten Blutkörperchen finden können. Es sind das diejenigen Fälle, wo der Körper den Kampf mit der Infektion nicht mehr aufnehmen konnte, wo also diejenigen reaktiven Erscheinungen fehlen, die zu den oben beschriebenen pathologisch-anatomischen Veränderungen geführt hätten.

Wir hatten unlängst Gelegenheit, zwei derartige Fälle zu beobachten. In einem Falle von kruppöser Pneumonie fanden wir ganz unerwartet bei der Sektion eine starke atrophische Leberzirrhose ohne besondere VergröBerung der Milz und ohne Aszites. Es war die Leiche eines alten, äußerst marantischen Mannes: Es bestand ein leichter Ikterus. In dem Abstrichpräparat aus. der Leber und der Milz konnten wir keine Erythrophagen finden. Das Knochenmark war in den Röhrenknochen nicht rot, sondern gallertartig schleimig; es floß wie. Gelée von der Oberfläche 
des zersägten Knochens. Solch ein Knochenmark ist selbstverständlich nicht imstande, die Formelemente des Blutes zu ersetzen - es ist vollständig erschöpft. Es hat da auch die Zerstörung der roten Blutkörperchen in Milz und Leber aufgehört. Die pathologische Anatomie lehrt uns ja, daß bei hohen Graden von Marasmus die muzinoide Degeneration des Knochenmarks auftritt.

Unser zweiter Fall, bei dem keine Erythrophagen zu finden waren, bezieht sich auf die Sektion eines tuberkulösen, stark marantischen Subjekts mit käsigen Veränderungen des gesamten Lungengewebes. Die Milz war etwas vergrößert, jedoch sehr derb und fibrös. Die Leber war blutarm. In diesem Organ war kein Erythrophag zu finden. Das Knochenmark erwies sich ebenfalls als gallertig.

Derartige negative Resultate erschüttern selbstverständlich nicht unsere Anschauung, die durch Tatsachen fest begründet ist. Im Gegenteil, sie bestätigen noch einmal ihre Richtigkeit und besagen bloß, daß die reaktiven Prozesse in den letzten Lebenstagen aufhören, und wir daher an der Leiche bloß das Resultat der früher stattgehabten Prozesse sehen, während die Ursache, die diese anatomischen Veränderungen hervorgerufen hat, nicht mehr existiert. Der Organismus hat im Kampfe seine Waffen verloren und unterlag. Diese negativen Fälle müssen bei der Nachprüfung dieser Arbeit in Betracht gezogen werden.

Die Leberzirrhose entwickelt sich, wie bekannt, am häufigsten unter dem Einflusse des Alkohols. Es ist eine allgemein bekannte Tatsache, daß die starken Alkoholiker anämisch sind und die Kliniker konstatieren, daß , sich bei den Alkoholikern eine große Milz viel früher nachweisen läßt, als eine Leberzirrhose, mitunter auch in den Fällen, wo eine Leberzirrhose überhaupt nicht auftritt" (M. $\mathrm{Roch}{ }^{15}$ ). Auf Grund dieser Tatsachen können wir mit großer Wahrscheinlichkeit voraussetzen, daß der Alkohol zu denjenigen Giften gehört, die eine Leberzirrhose hervorrufen. Es geschieht das nicht durch direkte Beeinflussung des Gewebes, sondern mit Hilfe der Erythrophagen der Milz, die sich bei den Alkoholikern in großer Menge vermehren, dann in die Leber gelangen, daselbst zu* grunde gehen und durch ihre Zerfallsprodukte zu einer Reizung und Wucherung des Bindegewebes führen. Die Tatsache, daß sich nicht bei allen Potatoren eine Leberzirrhose entwickelt, findet ihre Erklärung in den individuellen Verhältnissen (die Widerstandsfähigkeit der Leber bei verschiedenen Individuen ist nicht die gleiche). Ferner ist es auch möglich, daß, ähnlich wie im Tierexperiment bei der chronischen Vergiftung mit anämisierenden Giften, die Erythrophagen so wenig resistent sind, daß sie zum größten Teil bereits in der Milz zugrunde gehen, während sehr wenige von ihnen in die Leber gelangen und daher auch außerstande sind, Entzündungserscheinungen auszulösen.

Wir erlauben uns daher zu behaupten, daß nicht bloß die lienogenen Zirrhosen, wie B le i c hroe der (a. a. O. S. 455) es meint, sondern alle Zirrhosen ohne Ausnahmeals Folgeerseheinungen von anämischen Vorgängen im Körper aufzufassen sind. Es ist dabei gleichgültig, ob die Anämie dureh exogene Gifte (Alkohol, Malaria, syphilitische und tuberkulöse Infektion, Abdominaltyphus) ve r ursacht wird, oder durch endogene Gifte, wie solche z. B. bei 
anormaler Tätigkeit des Magen-Darmtraktus vorkommen. Es ist bekannt, daß man bei Leberzirrhosen, wie auch bei anderen Anämien, stets mehr oder weniger starke Veränderungen des Magens und Darms vorfindet. B l e i ch r o e d er (a. a. 0.) vertritt auf Grund von Literaturangaben ganz entschieden den Standpunkt, da $B$ eine Analogie zwischen den Blutkrankheiten und Leberzirrhosen besteht, da sie zu gleichen Veränderungen in einigen Organen führen.

Es existiert noch eine Krankheit, die nahe Beziehungen einerseits zu den Leberzirrhosen, anderseits zur Anämie hat. Es ist das die sog. Splenomegalie, die zuerst im Jahre 1882 von G a u ch e $\mathrm{r}^{16}$ beschrieben worden ist.

Wir wiesen bereits früher darauf hin, daß die Splenomegalie eine ständige Gefährtin der Leberzirrhosen ist. Sie ist besonders stark entwickelt bei der sog. hypertrophischen Zirrhose, bei welcher die Milz mitunter so groß ist, daß man von einer Hypersplenomegalie reden kann. Zugleich haben wir auch die nahen Beziehungen zwischen der Anämie und der Leberzirrhose festgestellt.

G a u ch er, der, wie bereits erwähnt, zuerst die Splenomegalie primitive beschrieben hat, war geneigt, diese Krankheit als eine sui generis aufzufassen. Jedoch bei der näheren Untersuchung seines Falles fand er außer der MilzvergröBerung eine progressive Anämie, Ekchymosen, eine Pigmentierung der Hant „dermapheisme“, Blutungen aus der Nase und dem Zahnfleisch und die übrigen Zeichen einer schweren Anämie. Die Leber war vergrößert, das Gewicht der Milz betrug $4.770 \mathrm{~g}$, der Leber $3.480 \mathrm{~g}$; in der letzteren waren deutliche zirrhotische Veränderungen wahrzunehmen.

Die nächsten Autoren (Collier, Picard et Ramond, Bowaird, Brill and $S$. Schlagenhaufer ${ }^{17}$ ) die nach $G a u c h$ er die Splenomegalie beschrieben haben, weisen darauf hin, daB als beständige Begleiterscheinung dieser Krankheit eine Anämie auftritt, wobei die Zahl der roten Blutkörperchen bis auf 1302000 und der Hämoglobingehalt bis auf $58 \%$ sank ( $\mathrm{S}$ e h l a g e $\mathrm{h} \mathrm{h}$ a $\mathrm{u} f \mathrm{e} \mathrm{r}$ ). In allen Fällen wurden auch Veränderungen des Knochenmarks gefunden: es erwies sich stets als rot. In der Leber ist das Bindegewebe immer mehr oder weniger gewuchert und das Organ selbst erscheint in der Mehrzahl der Fälle vergröBert.

Wir sehen folglich, daß die sog. Splenomegalie von $G$ a $u$ e her stets von einer Anämie, zirrhotischen Veränderungen in der Leber und einer Hyperplasie des Knochenmarks begleitet ist, und es erscheint uns daher unverständlich, daß diese Erkrankung als eine selbständige aufgefaßt wird.

Es ist auffallend, daß bei dieser Krankheit von allen Autoren bei der histologisehen Untersuchung der inneren Organe in der Milz, Leber, einigen Lymphdrüsen und im Knochenmark zahlreiche, große epitheliale Zellen gefunden wurden, die einen kleinen, mitunter auch mehrere Kerne enthalten und in ihrem Protoplasma Vakuolen aufweisen, die zum größten Teil gleichmäßig groß sind und daher eine gewisse Ähnlichkeit mit einer Bienenzelle besitzen; daher auch die Bezeichnung: wabige Vakuolisation.

S chlage $\mathrm{nh}$ a u f er bringt in seiner umfangreichen Arbeit über Splenomegalie sehr hübsche Präparate von der Milz und der Leber. Wir sehen da zahlreiche große Zellen, die sich in keiner Weise von unseren Erythrophagen unterscheiden und zum größten Teil in den Sinus und Venen der Milz liegen. Ich erlaube mir diese Zeichnungen wiederzugeben (s. Taf. IV, Fig. 9 a. 10), damit sie mit meinen Photogrammen verglichen werden können. Es wird zugegeben werden müssen, daß diese Zellen völlig identisch mit meinen Erythrophagen sind. 
Schlagenhaufer und die anderen Autoren sehen die in den Erythrophagen eingeschlossenen Gebilde nicht für Erythrozyten an, fassen sie vielmehr als Vakuolen auf, weil das Hämoglobin der roten Blutkörperchen vom Formalin ausgelaugt ist ( $S \mathrm{chl}$ a gen $\mathrm{h}$ a $\mathbf{u}$ f er konserviert seine Präparate nach der $\mathrm{K}$ a is e r lingsehen Methode).

Gaucher (a. a. 0.) faßt sie als epitheliale Gebilde auf und ist der Ansicht, dab es sich um ein primäres Epitheliom der Milz handelt. Bouwaird bezeichnet seinen Fall als eine endotheliale Hyperplasie der Milz.

Ähnliche Zellen fanden diese Autoren auch in den Lymphdrüsen, im Knochenmark und in der Leber. In der letzteren sammeln sie sich in solch grober Menge an und sind so nahe an einander gelagert, daß ,die Abgrenzung der einzelnen Zelle schwer gelingt". ( S ch lage n h a u f er, a. a. O. S. 131.) Wir sind der Ansicht, dab eben diese Schwierigkeit der mikroskopischen Untersuchung der Leber dahin geführt hat, daß die Autoren die Ansammlung von Erythrophagen übersehen konnten, welche der Kapillarwand der peripherischen Teile der Leberläppchen fest aufsitzen und die scheinbare Fortsetzung der Leberbalken bilden. Bei der ungeeigneten Bearbeitung der Präparate konnte das leicht passieren.

Wir finden also bei der Splenomegalie Ga u ch er denselben Zerstörungsprozeß der roten Blutkörperchen durch die Erythrophagen in der Milz, wo sie dann teilweise zerfallen (die Autoren weisen auf das Vorkommen von Hämosiderinklümpchen in der Milz hin), zum größten Teil jedoch mit dem Blutstrom in die Leber gelangen, daselbst endgültig zerfallen und durch ihre massenhaften Zerfallsprodukte in den peripherischen Teilen des Leberläppchens eine Reizung des interlobulären Bindegewebes mit konsekutiver Zirrhosenentwicklung hervorrufen.

Aus dem oben Angeführten ergibt es sich, daß die Splenomegalie sich durch nichts von der Leberzirrhose unterscheidet, da auch sie aus einer Anämie entsteht, welche durch eine erhöhte Phagozytierung der roten Blutkörperchen zustande kommt. Da in den meisten von verschiedenen Autoren beschriebenen Fällen von Splenomegalie in den verschiedenen Organen tuberkulöse Veränderungen gefunden worden sind, so ist anzunehmen, daß das tuberkulöse Virus dasjenige Gift ist, das in den meisten Fällen der sog. primären Splenomegalie die Erythrophagen zu erhöhter Tätigkeit anregt. Es ist auch nicht ausgeschlossen, daß die bereits früher erwähnten Gifte in ähnlichen Fällen eine gleiche Wirkung haben können. Es ist deshalb klar, daß bei den von uns betrachteten Krankheiten (Morb. Banti, Leberzirrhose und Splenomegalie Gaucher ) als Grundursache eine Anämie anzusehen ist, welche die Pathogenese der genannten Krankheiten erklärt. Diese Anämien sind als primäre aufzufassen, die durch erhöhte Tätigkeit der Erythrophagen hervorgerufen werden und die in mehr oder weniger ausgesprochenen quantitativen und qualitativen Veränderungen des Bluts bestehen und sich von den perniziösen Anämien nur durch die Intensität der Veränderungen des Bluts unterscheiden. Die qualitativen Veränderungen des Blutes bei der perniziösen Anämie, wie auch bei den oben genannten Krankheiten (der B a n t i schen Krankheit, den Leberzirrhosen und der Splenomegalie) sind in den Hauptzügen ein und dieselben und bestehen in dem Auftreten von jungen, nicht voll entwickelten Erythrozyten (Jugendformen) im Blute. $\mathrm{Zu}$ den letzteren zählen wir die polychromatophilen ( $\mathrm{G} \mathrm{r}$ a wit z a. a. O. S. 120), die kernhaltigen Zellen (Erythroblasten), Megalozyten und 
Mikrozyten ( Hayem, Eichhorst, Eisen loh ${ }^{1}$ )). In bezug auf die Poikilozyten bleibt die Frage offen, ob sie als degenerative oder Jugendformen, durch die erhöhte Neubildung von Erythrozyten entstanden, aufgefaßt werden müssen. Wir besitzen jedenfalls bisher keine einwandsfreien Beweise dafür, daß die Poikilozyten degenerative Formen sind. Übrigens ist die Zahl der Poikilozyten bei den Leberzirrhosen der B a n $t$ i krankheit und der Splenomegalie G a u c h er gewöhnlich eine recht geringe, während die körnigen Formen nur in den schwersten Fällen von perniziöser Anämie vorkommen.

Es besteht folglich der Unterschied zwischen der perniziösen Anämie und den drei oben genannten Krankheiten bloß in dem Grade der Veränderungen der roten Blutkörperchen: meistenteils in der Zahl und in dem Prozentgehalt an Hämoglobin.

Bei der perniziösen Anämie treffen wir fast beständig eine mehr oder weniger ausgesprochene Splenomegalie. Diese Milzvergrößerung kommt nach den Autoren durch Hyperplasie aller Gewebselemente zustande. Ausführlichere Untersuchungen der Milz bei diesen Anämieformen konnte ich in der mir zur Verfügung stehenden Literatur nicht ausfindig machen. Ich selbst verfüge über einige Beobachtungen von perniziöser Anämie, wo bei der Sektion die Milz stark vergrößert gefunden wurde. Auf Grund von unseren Beobachtungen und von Arbeiten von $\mathrm{He}$ in z ${ }^{18}$ über die Veränderungen des Milzgewebes bei künstlich durch Giftwirkung hervorgerufenen perniziösen Anämien muß man annehmen, daß bei dieser Krankheit unter dem Einfluß dieser Giftwirkung auch beim Menschen in der Milz eine erhöhte Erythrophagenbildung mit massenhafter Verschlingung von roten Blutkörperchen zustande kommt.

Sehr lückenhaft sind auch die Literaturangaben über die Veränderungen in der Leber bei der perniziösen Anämie.

Bekannt ist nur aus der Arbeit von $Q$ u i n c k e (und das ist für uns von großer Bedentung), daß bei allen plastischen, perniziösen Anämien der Eisengehalt in der Leber außergewöhnlich vermehrt ist. So finden wir normalerweise in $100 \mathrm{~g}$ Trockensubstanz der Leber $100 \mathrm{bis} 200 \mathrm{mg}$ Eisen, bei der perniziösen Anämie erreicht die Menge mitunter $1900 \mathrm{mg}$. Der große Eisengehalt der. Leber weist auf eine große Zerstörung der roten Blutkörperchen hin. Diese Zerstörung findet natürlich nicht im Blut statt, sondern kommt nach unserer festen Überzeugung durch die erhöhte Verschlingung der Formelemente des Blutes durch die Erythrophagen der Milz und durch deren Zerfall in der Leber, wie oben bereits angeführt, zustande.

Die Regeneration der roten Blutkörperchen geht wie bei den andern Anämien im Knochenmark vor sich; bei den perniziösen Anämien finden wir dasselbe stets rot und lymphoid. Eine Ausnahme bilden nur diejenigen Fälle von sogenannter aplastischer Anämie, die eine Folge der Aufhebung der blutbildenden Funktion des Knochenmarks sind, wie wir es bei den 'Tumoren des Knochenmarks beobachten. Merkwürdig dabei ist, daß in diesen Fällen eine Siderose der Leber nicht angetroffen wird ( $\mathrm{L}$ e $\mathrm{u} b \mathrm{e}^{19}$ ). Veränderungen im Magen-Darmkanal bei der perniziösen Anämie sowie bei den oben angeführten Krankheiten sind immer vorhanden und führen zu mehr oder minder ausgeprägten Atrophien, die durch chronische Gastroenteritiden erzeugt werden.

1) Siehe Grawitz, a. a. 0 . 
Auf Grund der angeführten Tatsachen behaupten wir, daß bei dem Morbus B a n tii , den Leberzirrhosen, der Splenomegalie und der perniziösen Anämie folgende Organveränderungen gefunden werden:

1. Eine Anämie mit quantitativen und qualitativen Veränderungen des Blutes;

2. eine mehr oder weniger ausgesprochene Milzvergrößerung;

3. Veränderungen in der Leber - Siderosis oder zirrhotische Prozesse;

4. atrophische Veränderungen des Magen-Darmkanals;

5. rotes Knochenmark.

Deshalb müssen alle oben angeführten Krankheiten zu einer Gruppe der primären Anämien zusammengefaßt werden. Die hauptsächlichsten klinischen Unterschiede der einzelnen Formen hängen von dem Vorherrschen der einen, oder von mehreren der oben angeführten Veränderungen ab.

Wenn schwere Blutveränderungen das klinische Bild beherrsehen, dann sprechen wir von einer perniziösen Anämie und betrachten die andern Symptome als Begleiterscheinungen; falls Symptome eines indurativen Leberprozesses vorherrschen, sprechen wir von einer Leberzirrhose. Wenn der Kliniker eine große Milz antrifft, für deren Entstehung er keine besondere Erklärung finden kann, so spricht er von einer Splenomegalie. Wenn jedoch eine Kombination oben genannter Symptome vorliegt, so sprechen wir von Morbus B a n ti i.

Es besteht also zwischen diesen einzelnen Krankheitsformen ein bloß quantitativer Unterschied. Wie sonderbar er auch erscheinen mag, so muß doch die Krankheit, die in einer Vermehrung der Zahl der roten Blutkörperchen besteht, die sog. Erythrämie oder Polyglobulie Vaque z zu dieser Gruppe der Blutkrankheiten hinzugerechnet werden.

Wie bekannt, ist die Polyglobulie von einer Splenomegalie (wir selbst haben in der letzten Zeit zwei klinische Fälle von Erythrämie beobachtet), einer Lebervergrößerung und einer Hyperplasie des Knochenmarks begleitet. In pathologischanatomischer Hinsicht ist diese Krankheit noch wenig oder gar nicht studiert worden, wir können jedoch annehmen, daß die Milzvergrößerung bei derselben durch den erhöhten Zerfall der roten Blutkörperchen zustande kommt, da andere Gründe für diese Splenomegalie nicht vorliegen. Auf Grund unserer Untersuchungen anläßlich des Falles von B a n t i scher Krankheit und auf Grund der Arbeit von D o n itz ${ }^{20}$, laut welcher der erhöhte Zerfall der roten Blutkörperchen in der Milz zu einer Vergrößerung dieses Organs führte, können wir mit großer Wahrscheinlichkeit annehmen, daß auch bei der Erythrämie ein erhöhter Zerfall der roten Blutkörperchen in der Milz stattfindet; dafür spricht auch, daß bei dieser Krankheit im Harn beständig Urobilin und, wie unsere eigene Beobachtung gezeigt hat, auch im Blute Jugendformen der Erythrozyten gefunden werden. Wenn wir uns auf diesen Standpunkt stellen, so ist auch die LebervergröBerung

1) Siehe $R$ awitz a. a. 0 . 
leicht erklärt: es gehen in ihr im erhöhten Maße Zellen zugrunde, die Erythrozyten verschlungen haben und aus der Milz in die Leber gelangt sind.

Da wir es jedoch nicht mit einer Verminderung der Zahl der roten Blutkörperchen, sondern mit einer Vermehrung derselben $\mathrm{zu}$ tun haben, so müssen wir selbstverständlich eine erhöhte Bildung derselben in den blutbildenden Organen voraussetzen. Das Knochenmark ist auch tatsächlich bei der Polyglobulie rot und um bei einem verstärkten Zerfall von roten Blutkörperchen eine Vermehrung derselben zu finden, ist eine besonders stark erhöhte Neubildung dieser Zellen notwendig. Wenn also zwischen diesen einander entgegengesetzten Vorgängen kein Gleichgewicht besteht, und die Neubildung neben dem Zerfall prävaliert, so resultiert daraus eine Zellenvermehrung - eine Polyzytämie.

Wir finden in der Literatur zwei Erklärungen für diese Krankheit. Die einen Autoren sind der Ansicht, daß die Vermehrung der roten Blutkörperchen durch die erhöhte Reproduktion derselben bei normalen Zerfallsprozessen zustande kommt. Nach der Meinung der andern kann eine Erythrämie auftreten, wenn bei normaler Bildung von roten Blutkörperchen die Zerfallsprozesse verlangsamt sind. Wir können uns mit keiner dieser Theorien einverstanden erklären, weil dabei die Entstehung der Splenomegalie, die in allen Fällen dieser Krankheit angetroffen wird, nicht erklärt wäre.

Wir müssen unsere Aufmerksamkeit auf noch eine Krankheit lenken, die sog. Pseudoleukämie. Das Wesen dieser Krankheit und ihr klinisches Bild sind so dunkel, daß Virchow geneigt war, in ihr ein „Mischmasch“ zu sehen. Die wichtigsten Merkmale der $\mathrm{Hodgk}$ in s schen Krankheit sind folgende: eine quantitative und teilweise qualitative Anämie, Splenomegalie, Vergrößerung der peripherisehen Lymphdrüsen und Hyperplasie des Knochenmarks. Diese Symptome werden von einer Temperaturerhöhung vom unregelmäßigen Typus, wie auch bei jeder anderen primären Anämie, begleitet. Der wesentlichste Unterschied dieser Krankheit von den von uns erwähnten anämischen Zuständen besteht in der Vergrößerung der Lymphdrüsen. Wir finden in der Literatur keinerlei deutliche Angaben über den Befund in den Lymphdrüsen bei der perniziösen Anämie und der Leberzirrhose, verfügen auch nicht über eigene Untersuchungen. Wir wissen selbst nicht, ob sie überhaupt bei diesen Krankheiten vergrößert sind, jedoch fand $S \mathrm{chl}$ a enh a ufer, wie wir früher gesehen haben bei der primären Splenomegalie, in den hyperplasierten Lymphdrüsen im Gewebe der Lymphknoten sehr charakteristische Veränderungen, die in dem Auftreten von großen Zellen mit sog. „wabiger Vakuolisation" bestehen. Diese Zellen sind so typisch und unsern Erythrophagen derart ähnlich, daß wir in dieser Hinsicht nicht den geringsten Zweifel hegen. Es wird sich auch ein jeder davon leicht überzeugen, wenn er sich die Zeichnung von S e hla g e n h a u f e r (Fig. 10) ansieht.

Wir sehen folglich, daß sich bei der Splenomegalie in den Lymphdrüsen derselbe Prozeß des Verschlingens der roten Blutkörperchen abspielt. Es läßt sich sehr leicht diese Erscheinung dadurch erklären, daß ein und dieselbe Ursache, 
die die Vermehrung der Erythrophagen in der Milz anregt, eine ähnliche Wirkung auch auf die Elemente der Lymphdrüsen ausüben $m u B$, in denen dann ebenfalls eine Vermehrung der Erythrophagen stattfindet. Es ist das um so verständlicher, da doch die Lymphdrüsen und die Milz einen sehr ähnlichen histologischen Bau besitzen, besonders wenn wir die Lymphdrüsen mit den Malpighischen Körperchen der Milz vergleichen. Unter dem Einfluß der Toxine, die im Blut kreisen, entstehen aus den Zellen der Malpig hischen Körperchen die Erythrophagen, während in den Lymphdrüsen unter denselben Bedingungen analoge Zellen auftreten. In unserm Fall von B a n t i scher Krankheit erwies sich eine starke Hyperplasie der Mesenterialdrüsen; es ist höchstwahrscheinlich, daß wir auch in ihnen die Erythrophagen gefunden hätten, leider hatten wir aber zu unserm größten Bedauern keine Stückchen aus diesen Drüsen zur mikroskopischen Untersuchung genommen.

Wir müssen hier jedoch ganz allgemein bemerken, daß, wenn auch in der Literatur keinerlei Angaben über derartige Veränderungen in den Lymphdrüsen bei den perniziösen Anämien, wie auch bei den Leberzirrhosen, vorhanden sind, daraus durchaus nicht folgt, daß sie auch in der Wirklichkeit nicht vorhanden sind. Ich bin der Ansicht, daß die Veränderungen, die von $S \mathbf{c h l} l$ a g e $\mathrm{nh}$ a u f e r bei der Anämie beschrieben sind, auch bei den primären Anämien sich vorfinden müssen.

Dafür wissen wir aus den Arbeiten von S t e r n b e r $\mathbf{g}^{\mathbf{2 1}}$, daß bei der Hyperplasie der pseudoleukämischen Drüsen in ihnen ,,eine große Menge von besonderen Zellen zu sehen ist, die ein- oder mehrkernig sind, ein reiches Protoplasma und einen großen runden, polymorphen und sehr intensiv färbenden Kern besitzen. Diese Zellen erinnern sehr an die Geschwulstzellen und es finden sich Utbergangsformen zwischen den Endothelzellen der Kapillaren und diesen großen Formen". Ob diese großen Zellen rote Blutkörperchen oder „wabige Vakuolen“ enthalten, erwähnt der Autor nicht.

Auf Grund der neuesten Untersuchungen ( $\mathrm{Grawitz}$, S. 476) werden drei histologisch und ätiologisch voneinander unterschiedene Veränderungen der Lymphdrüsen bei der Pseudoleukämie als anatomische Grundlage der Krankheit angenommen:

1. gewöhnliche Hyperplasie - Lymphoma simplex,

2. tuberkulöse Hyperplasie -.- Lymphoma tuberculosum,

3. Hyperplasie bei tertiärer Syphilis - Lymphoma gummosum.

$S$ ter $n$ berg fand die uns interessierenden Zellen bei den tuberkulösen Lymphomen, L ö w en b a ch ${ }^{22}$ - bei der Syphilis, bei welcher Krankheit ihre große Ähnlichkeit mit den endothelialen und epithelialen Zellen hervorgehoben wird. Diese Zellen sind nach Stern * b e r g sehr groß, ihr Protoplasma granuliert, jedoch erwähnt er nichts von etwaigen Einschlüssen in denselben. Es ist sehr möglich, daß ähnliche Zellen auch bei den einfachen Hyperplasien (falls solche existieren) der pseudoleukämischen Drüsen vorkommen, und man kann voraussetzen,

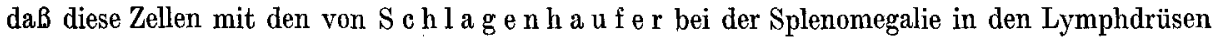
gefundenen identisch sind.

In der Mehrzahl der Fälle von Pseudoleukämien ist die Milz vergrößert, von mäBiger Konsistenz und weist deutliche Zeichen eines hyperplastischen Prozesses auf, der in der Vergrößerung der M a l p i g h i schen Körperchen und der Vermehrung der Zellelemente der Pulpa besteht. Bleichroeder (a. a. 0. S. 447-448) findet eine große Ähnlichkeit zwischen der pseudoleukämischen Milz und der Milz bei der Leberzirrhose, der perniziösen Anämie und der anderen Blutkrankheiten. In all diesen Fällen fand er einen vermehrten Gehalt an Eisen, der auf einem ver. 
stärkten Zerfall der roten Blutkörperchen hinwesst, pesonders große Zellen - die „Reizungsformen“ nach $\mathrm{T}$ ü $\mathrm{r} \mathrm{ck}$ und eine mehr oder weniger starke Entwicklung von Bindegewebe.

Nach Z i e gl e r (a. a. O. S. 129-131) treffen wir bei der Pseudoleukämie eine tuberkulöse Splenomegalie an mit oft nur wenig entwickelten mitunter auch ganz fehlenden käsigen Veränderungen; es treten dabei großzellige Knötchen - „eigenartige zellige Wucherungen mit sehr un-

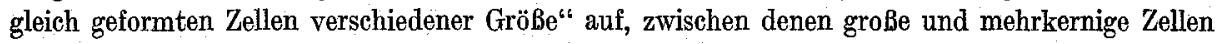
angetroffen werden. „Ist solch eine tuberkulöse Splenomegalie mit entsprechenden Veränderungen in den Lymphdrüsen verbunden, so kann die Erkrankung klinisch und anatomisch das Bild der Pseudoleukämie bieten."

Wir können daher mit großer Wahrscheinlichkeit voraussetzen, wie wir uns auch an den Milzen von Tuberkulösen überzeugt haben, daß auch in der pseudoleukämischen Milz in erhöhtem Maße Erythrophagen auftreten und eine quantitative Anämie verursachen.

In der Mehrzahl der Fälle pflegen die Pseudoleukämien, wie bereits oben erwähnt, bei der Tuberkulose vorzukommen. C. Stern berg (a. a. 0.) konnte in 18 klinischen Fällen von Pseudoleukämie 15 mal eine Tuberkulose konstatieren. Andere Autoren fanden sehr oft bei der bakterioskopischen Untersuchung Tuberkelbazillen in pseudoleukämischen Drüsen (A s ka . $\mathrm{n}$ a $\mathrm{z} \mathrm{y}^{23}$ ), wie auch besonders bei der Überimpfung des Saftes der pseudoleukämischen Drüsen auf Tiere, selbst in den Fällen, wo keinerlei für die Tuberkulose charakteristische mikroskopische Veränderungen vorhanden waren ( $\mathrm{F}$ is c h e r ${ }^{24}$ und $\mathrm{S}$ a b r a z è s ${ }^{25}$ ).

Vielleicht könnte auch in der Tatsache des Auftretens in den pseudoleukämischen Drüsen von Erythrophagen, die eine verschiedene Gestalt, Form und Protoplasma haben, je nach den in ihnen vorhandenen Einschlüssen, die Erklärung für die ,polymorphzelligen Lymphome“ zu finden sein, die nach Ziegler als Ausdruck einer „,besonderen Tuberkuloseform“" in den pseudoleukämischen Drüsen aufzufassen sind.

Über den Zustand der Leber bei den pseudoleukämischen Prozessen ist uns nichts bekannt, jedoch müssen, falls in der Milz, wie wir fest davon überzeugt sind, zahlreiche Erythrophagen auftreten, dieselben selbstverständlich auch in der Leber gefunden werden, wohin sie notgedrungen mit dem Blutstrom gelangen müssen, daselbst endgültig zerfallen, in großer Menge das Material zur Bildung von Galle und der Ablagerung von Hämosiderin liefern und in vereinzelten Fällen auch zur Entwicklung von interstitiellen Veränderungen führen.

Es bestehen folglich zwischen den Pseudoleukämien und den oben genannten Krankheiten (der Banti schen Krankheit, der primären Splenomegalie, der Leberzirrhose, der perniziösen Anämie) einerseits und der Tuberkulose (resp. der Syphilis) andrerseits sehr nahe Beziehungen, die sich darin äußern, daß die Erscheinungen der Anämie bei allen diesen Erkrankungen durch besondere Gifte verursacht werden, unter deren Einfluß in der Milz, in den Lymphdrüsen (möglicherweise auch in dem Knochenmark) eine erhöhte Neubildung von normalerweise existierenden besonderen Zellenphagozyten auftritt, die unter anderm auch die roten Blutkörperchen verschlingen und utilisieren, sie dann mit dem Blutstrom. in die Leber bringen, wo dann die Erythrozyten endgültig zerfallen.

Doch welche Gifte sind das?

Um an die Lösung dieser Frage heranzugehen, benutzten wir die Erfahrungen, die uns die Hämopathologie liefert.

Nach Gra w i t z (a. a. O. S. 232-233) gibt es zweierlei Blutgifte, die zu einer Anämie führen.

Die einen zerstören die roten Blutkörperchen im kreisenden Blute, indem sie dieselben auflösen — das sind die sogenannten hämolytischen Gifte.

Die anderen Gifte üben eine sogenannte plasmotrope Wirkung aus, die darin besteht, daß diese Gifte, ohne die Elemente des Blutes selbst zu zerstören, sie derart schädigen, daß sie in großer 
Menge in der Leber und Milz zugrunde gehen. Zu diesen Giften gehört das Phenylhydrazin und seine Salze: Pyrodins. Azethyphenilhydrazin (auch Hydrazetin genannt), Azetylpropionsäure (Antitermin oder Ortin) u. a.

Die sogenannte plasmatrope Wirkung des Giftes der zweiten Kategorie erscheint uns unverständlich, denn es ist schwer zu verstehen, weshalb die Erythrozyten nur in den erwähnten Organen zugrunde gehen und weshalb bloß ein Teil derselben und nicht alle unter dem Einfluß dieser Gifte verändert werden, denn, falls zu wenig Gift eingeführt worden ist, wäre ihre Wirkung in dem Gesamtblut ungenügend, bei einer stärkeren Dosis müßten alle Erythrozyten verändert werden und auch in den genannten Organen zerfallen.

Bereits in der Arbeit von $\mathrm{He}$ in z selbst (a. a. 0.) können wir einen Hinweis finden, daß die Verhältnisse anders liegen, als der Autor es sich vorgestellt hat. H e in z weist darauf hin, $\mathrm{da} B$ in den roten Blutkörperchen unter dem Einfluß des Phenylhydrazins und ähnlich wirkender Gifte in den Gefäßen der Milz - eine Körnchenbildung auftritt, wahrscheinlich infolge einer besonderen Organisation der Gefäßendothelien; sie schrumpfen und verwandeln sich in den Zellen der Milz zu einem körnigen Pigment. Er sagt des weiteren, daß diese Zellen stark vermehrt sind, an Größe sehr zunehmen, und in den Gefäßen, wie auch in dem Gewebe zu finden sind. Sie sind mit den Zerfallsprodukten der roten Blutkörperchen gefüllt, die infolge der morphologischen und ehemischen Veränderungen der in den Zellen eingeschlossenen Erythrozyten entstehen, indem die Zellkerne allmählich sich auflösen und vollständig verschwinden. H e in z hält diese Zellen für Endothelien, welche durch Versehlingung von Trümmern der Erythrozyten anormal gewachsen sind, und glaubt, daß primär die roten Blutkörperchen unter dem Einfluß des Giftes verändert und zerstört werden und erst dann die Phagozyten der roten Blutkörperchen auftreten.

Es ist weit natürlicher, sich vorzustellen, daß diese zweite Gruppe der anämisierenden Gifte bei einer mehrfachen Einführung in den Organismus die in der Milz normalerweise vorhandenen Erythrophagen zu einer Vermehrung anregen; infolgedessen wird auch eine immer größer werdende Anzahl von roten Blutkörperchen, die mit diesen Zellen in Berührung kommen, verschlungen. Diese Anschauung steht in keinem Widerspruch zu den Erscheinungen der Chemotaxis, die verstärkt wird durch den Einfluß der mehrfachen Einführung von dem Körper fremdartigen Stoffen, mögen das bakterielle Gifte oder andere chemische Stoffe sein.

Wir wiederholten die Versuche von $\mathrm{He}$ in $\mathrm{z}$ an einem Kaninchen, indem wir kleine Dosen von Pyrodin einführten, um keine akute Intoxikation zu bekommen. Da die therapeutische Dosis für den Menschen 0,1 beträgt, so nahmen wir für das Kaninchen von 11/2 Kilo Gewicht 2,5 mg und spritzten die Lösung täglich in die Venen des Ohres ein. Vor dem Versuche betrug das Gewicht des Kaninchens $1580 \mathrm{~g}$; die Temperatur schwankte zwischen $37^{\circ} \mathrm{C}$. und $38^{\circ} \mathrm{C}$. Die Zahl der roten Blutkörperchen betrug in einem Kubikmillimeter 5900000 , der weißen 5100 , der Prozentgehalt des Hämoglobins, nach Flei schl berechnet, $85 \%$. Die roten Blutkörperchen und die Leukozyten stellten keine besonderen morphologischen Veränderungen vor.

Bereits am vierten Tage, folglich nach der dritten Einspritzung des Giftes, fand sich eine Polychromatophilie, die Zahl der Erythrozyten sank ein wenig und betrug 5780000 , die der weißen stieg bis auf 5400 an. Am fünften Tag treten, wenn auch bloß in wenigen Exemplaren, kernhaltige Erythrozyten mit polychromatophilem Protoplasma auf. Die Temperatur erreichte $39^{\circ} \mathrm{C}$. Das Gewicht fiel bis auf $1562 \mathrm{~g}$. Am achten Tage betrug die Temperatur $38,2^{\circ}$, die Zahl der Erythrozyten 5650000 . Es traten zahlreiche zyanophile, kernhaltige sowie kernlose Zellen auf, sehr viele Zellen mit mehr oder weniger ausgesprochenem Austritt der Kerne aus dem Protoplasma, mitunter auch nackte Kerne, die in bezug auf Größe und Eigenschaften den Kernen der Erythroblasten entsprechen.

Am neunten Tage betrug der Hämoglobingehalt nur noch 60\%; im Blute traten außer den vorhin erwähnten Formen noch Makro- und Mikrozyten auf, wenn auch freilich in geringer Anzahl; außerdem waren auch Blutschatten vorhanden. 
Am fünfzehnten Tage traten zum ersten Male Poikilozyten auf; die Temperatur betrug $38^{\circ} \mathrm{C}$. bis $38,5^{\circ} \mathrm{C}$. Endlich am siebzehnten Tage wurde das Kaninchen nach stattgefundener Blutuntersuchung durch einen Stich in das verlängerte Mark getötet. Das Gewicht betrug $1670 \mathrm{~g}$ (Vermehrung um $90 \mathrm{~g}$ ); die Zahl der Erythrozyten 4720000 (Verminderung um 1180 000), der weißen 7225 (Vermehrung um 1825); Hämoglobingehalt $=47 \%$ (Verminderung um $38 \%$ ). Das Blut bestand zu einem großen Teil aus Polychromatophilen, mit und ohne Kern, wenigen Mikrozyten, zahlreichen Makrozyten, die immer polychromatophil waren; die Poikilozyten waren auch jetzt in geringer Zahl vorhanden. Körnige Formen waren kein einziges Mal während der Untersuchung zu sehen.

Bei der Sektion erwies sich die Milz im Vergleich zu der eines Kaninchens von ungefähr gleichem Körpergewicht vergrößert, ihre Kapsel gespannt, das Gewebe dunkelrot, die Pulpa locker, leicht abstreifbar, die M a I p i g h i schen Körperchen deutlich wahrzunehmen. Die Leber ohne besondere Veränderungen. Das Gewicht der Milz beträgt $1,7 \mathrm{~g}$ (unter normalen Verhältnissen $0,78 \mathrm{~g}$ ); die Länge $5,5 \mathrm{~cm}$, Breite ungefähr $1 \mathrm{~cm}$, die Dieke 0,5 bis $0,7 \mathrm{~cm}$; das Gewicht der Leber $73 \mathrm{~g}$.

Bereits in dem Abstrichpräparat von der Milzpulpa, in einer isotonischen Lösung untersucht, konnte man viele Erythrozyten finden, die zum größten Teil veränderte Erythrozyten, ihre Trümmer oder bloß rotbraunes Pigment enthielten, während die freien roten Blutkörperchen aus der Milz keinerlei Zerfallserscheinungen aufwiesen.

Zwecks Anfertigung von Präparaten wurden Stückchen aus der Leber in Azeton und der Flüssigkeit von $\mathrm{Ku}$ lts chitzky fixiert.

Bei der mikroskopischon Untersuchung der Milz ergab sich folgendes: die Sinus und Venen sind mit Blut überfüllt, der Inhalt der Gefäße besteht zum größten Teil aus roten Blutkörperchen, die in verschiedenem Grad gefärbt sind; der Unterschied zwischen den Mono- und Polychromatophilen kommt hier wenig zum Ausdruck; es sind viele kernhaltige Formen und nackte Kerne vorhanden; keine gekörnte Zelle, auch keine Erythrozytentrümmer. Viele Leukozyten und sehr zahlreiche große Zellen, die rote Blutkörperchen enthalten, mit und ohne Kerne, ihre Trümmer, rotbraunes Pigment oder bloß Blutschatten. Eine Abbildung eines Erythrophagen in dem Milzsinus des Kaninchens ist auf dem Photogramm (s. Fig. 11, Taf. IV) abgebildet. Auf dieser Zeichnung gelangte in dem Fokus bloß dieser eine Erythrophag, während das übrige Feld undeutlich zum Vorschein kam. In den Präparaten lassen sich alle Phasen des Zerfalls der Erythrophagen verfolgen, wobei es sich erweist, daß hier sehr viele im Zerfall begriffene Formen vorhanden sind und bloß selten und auch nur innerhalb der Blutgefäße (in den Sinus und Venen) unveränderte Erythrophagen auftreten, die einen gut färbbaren, recht großen Kern enthalten, welcher irgendwo in der Peripherie in einem etwas verdickten Protoplasmasaume liegt und sich mit Eosin (bei der G i e m s a färbung) intensiv färbt und die in ihren Zelleibern Erythrozyten, die oft kernhaltig sind, eingeschlossen haben. Außerhalb der Gefäße der Milz kommen in der Pulpa bloß zerfallende Formen der Erythrophagen in allen Stadien des Zerfalls vor. Die Zahl der Erythrophagen in der Milz ist sehr groß: im Gesichtsfelde können bei einer mittleren Vermehrung dieser Zellen gegen 40 Exemplare angetroffen werden.

Sehr interessante Erscheinungen weisen die Mal p i gh i schen Körperchen auf. Sie sind stark vermehrt und mehr oder weniger vergrößert. Diese Vergrößerung kommt durch eine Hyperplasie der Zellelemente zustande. Auf dem abgebildeten Photogramm (Fig. 12, Taf. IV) sieht man mitotische Kernteilungsfiguren der lymphoiden Zellen des Malpigh ischen Körperchens. Viele Zellen des Malpighischen Körperchens sind hypertrophiert, an welchem Prozeß die Zelle wie auch der Kern beteiligt sind. Besonders zahlreiche große Zellen befinden sich in der Peripherie des Malpigh ischen Körperchens; in einigen von ihnen kann man einen oder mehrere wenig veränderte Erythrozyten sehen, - es sind das die ganz jungen Erythrophagen.

Aus dieser Beschreibung der Zellenelemente des Malpigh i schen Körperchens des Kaninchens, das an einer chronischen Pyrodinvergiftung zugrunde ging, geht 
mit Sicherheit hervor, dab die Erythrophagen aus den Malpighi schen Korperchender Milz, infolgederVermehrung und Hypertrophieder lymphoiden Elemente, entstehen und daß wirdarindie Hauptaufgabeder Malpighischen Körperchen sehen müssen.

- Zur Illustration des Umwandlungsprozesses der lymphoiden Zellen in die Erythrophagen sind auf dem Mikrophotogramm (Fig. 13, Taf. IV) drei Zellen abgebildet, die in dem Sinus liegen, der den Rand des M a l p i g h i schen Körperchens umspült, dessen zentraler Teil auf der vorigen Zeichnung abgebildet ist. Die Zelle, die rechts liegt, hat einen großen in mitotischer Teilung begriffenen Kern; die Zelle in der Mitte ist kleiner als die vorige und enthält einen Kern, der in ruhendem Zustand sich befindet (sie erwies sich nicht im Fokus, weshalb sie auch nicht anf dem Photogramm zu sehen ist, da sie in einer anderen Fläche liegt); links befindet sich ein Erythrophag, der bereits einige rote Blutkörperchen verschlungen hat und im Zerfall begriffen ist.

Diese Bilder sind so prägnant, daß es keinem Zweifel unterliegen kann, daß die Malpighischen Körperchen der Milzals Geburtsstäte der Erythrophagen anzusehen sind. Eine weitere Bestätigung dafür liegt in der Tatsache, daß die meisten Erythrozyten um die Malpighischen Körperchen herum und in ihrer Nähe angetroffen werden.

Unsere Anschauung steht in keinem Widerspruch mit den Literaturangaben.

So lesen wir z. B. bei Dominici ${ }^{26}$, daß die M a l p i g i schen Körperchen an der Bildung der Zellenelemente der Pulpa teilnehmen, die sich dann in Myelozyten und andere Zellen umwandeln.

Sehr übersichtliche Bilder erhalten wir, wenn wir die Präparate aus der Milz vor der Färbung mit Ferro-Zyankali und Salzsäure bearbeiten, um das in ihnen enthaltene Hämosiderin zum Vorschein zu bringen.

Infolge dieser mikrochemischen Reaktion wird das Präparat infolge des großen Gehalts an Eisen sehr schnell dunkelblau. Die mikroskopische Untersuchung lehrt, daß die Klümpchen Eisen zum größten Teil den Erythrophagen entsprechen, so daß fast alle Erythrophagen der Milz des Kaninchens eine mehr oder weniger deutlich ausgesprochene Reaktion zeigen und nur wenige eine solche vermissen lassen. Daraus folgt, daß der Prozeß des Freiwerdens des Eisens in den Erythrozyten unter dem Einflusse des Pyrodins sehr schnell und sehr energisch in den Erythrophagen der Kaninchenmilz vor sich geht. Außerdem geht infolge der Wirkung dieses Gifts, wenigstens beim Kaninchen, der ZerfallsprozeB der Erythrophagen in der Milz selbst in großem Maßstabe vor sich, da bei dieser Behandlung der mikroskopischen Präparate in den Sinus und Venen, wie auch hauptsächlich in den Zellelementen der Milzpulpa eine große Menge zerfallender Exemplare gefunden wird.

Es ist merkwürdig, $\mathrm{d} \lambda \mathrm{B}$ man in den Erythrophagen selbst nicht bloß voll ausgebildete rote Blutkörperchen, sondern auch junge kernhaltige finden kann. Daraus folgt, daß in den Milzgefäßen nicht die absterbenden oder bereits zerfallenen Erythrozyten verschlungen werdcn, wie es $\mathrm{H}$ e i n z (a. a. 0.) voraussetzt, sondern all die Zellelemente, die mit den Erythrophagen in Berührung kamen, gleichgültig ob es ein vollentwickelter oder junger Eirythrozyt ist, oder gar ein weißes Blutkörperchen,

Bei den anämischen Zuständen, die durch die bereits früher untersuchten Krankheiten hervorgerufen werden, finden wir ebenfalls keinerlei zerfallende Flemente in den Blutgefäßen der Milz außer in den Erythrophagen: die Trümmer, die in Form von Pigmentklümpchen in der Pulpa angetroffen werden, treten erst infolge des Zerfalls der ganzen Zelle auf, welche die roten Blutkörperchen enthielt. 
Auch unter normalen Verhältnissen fressen die Erythrophagen, wie wir bereits früher erwähnt haben, nicht die absterbenden Zellen, sondern alle ohne Auswahl, die mit dem lockeren, klebrigen Protoplasma der Phagozyten in Berührung kommen.

Die Leber des Kaninchens war wenig verändert; ihre Zellen unterschieden sich in keiner Weise von den normalen, wie auch das Bindegewebe der Gli s s o n sehen Kapsel keinerlei Veränderungen aufwies. Die Erythrophagen waren hier verhältnismäßig nicht zahlreich, befanden sich in den peripherischen Teilen der Läppchen in ihren Kapillaren und zeigten alle eine deutliche Reaktion auf Eisen, das auch in den Leberzellen nur in geringer Menge vorhanden ist. Wenn wir jedoch diese Leber mit derjenigen eines gesunden Kaninchens vergleichen, so ergibt sich trotzdem ein sehr starker Unterschied. In der normalen Leber ist es sehr schwer, Erythrophagen zu finden, während sie in unserem Falle in jedem Leberläppehen, wenn auch nicht in allen Kapillaren, angetroffen werden.

Bei der Untersuchung des Knochenmarks erhielten wir das typische Bild einer ausgesprochenen Zellhyperplasie dieses Organs, infolge verstärkter Blutbildung.

Wir finden folglich, daß bei der ehronischen Vergiftung des Kaninchens mit in das Blut eingeführten kleinen Dosen von Pyrodin, eine Anämie (quantitative, wie auch qualitative) a ufritt, welehehervorgerufen wird durch die Verschlingung der roten Blutkörperchen in den Milzgefäßen, und zwar dureh besonders große Zellen, die Erythrophagen, die dannderartschnell samtihrem Inhaltzerfallen, daB bloB wenige die Leber erreichen. Als Geburtsstättedieser merkwürdigen Zellen müssen die Malpighischen Körperchender Milzangesehen werden, deren Proliferation durch das Giftangeregt wird. Es tritt folglich unter dem Einflusse des Giftes (in unserem Falle des Pyrodins) der Zerfall der Zellen, die in großen Massen die roten Blutkörperchen verschlungen haben, hauptsächlich in der Milz des Tieres auf, während in der Leber dieser Prozeß nur in geringem Grade ausgesprochen ist.

Wir wissen bereits, daß die massenhaften Zerfallsprodukte der roten Blutkörperchen, die in der Leber des Menschen bei den anämischen Zuständen angetroffen und durch die Erythrophagen vermittelt werden, mitunter zur Bildung einer Zirrhose führen. Es ist nun selbstverständlich, daß wir derartige zirrhotische Prozesse in der Leber des Kaninchens, selbst bei längerer Dauer der Versuche, nicht finden werden, da doch, wie wir gesehen haben, bei denselben diese Zerfallsprodukte der roten Blutkörperchen in der Leber nur in geringem Maße angetroffen werden. Ich glaube, daß in diesem Zustande die Ursache zu suchen ist, weshalb es den Autoren nie gelang, auf künstlichem Wege bei den Tieren eine Leberzirrhose hervorzurufen weder mit Pyrodin noch mit andern Giften, speziell auch nicht mit Alkohol.

Es müssen in dieser Beziehung Kontrollversuche, namentlich mit Alkoholvergiftung, angestellt werden, wir können jedoch a priori behaupten, daß die Mißerfolge der Autoren bei der Vergiftung der Tiere mit Alkohol von der Natur und der Art der Einführung des Giftes selbst abhängig sind, wie auch hauptsächlich von den individuellen Eigenschaften der Tiere, deren Erythrophagen sich weniger wider- 
standsfähig als beim Menschen erweisen, oder, was auf dasselbe hinauskommt, daß die Gifte, die die Proliferation dieser Zellen hervorrufen, zugleich ihr Protoplasma stark schädigen; infolgedessen gehen sie leicht zugrunde und bloß wenige erreichen die Leber. Unter derartigen Bedingungen kann sich eine Splenomegalie, aber keine Leberzirrhose entwickeln.

Auch beim Menschen kommt es infolge der Alkoholwirkung nicht immer zur Entwicklung einer Leberzirthose: es gibt doch so viele Säufer auf der Welt und doch treffen wir die Zirrhotiker bei weitem nicht so häufig an.

Viele Autoren weisen darauf hin, daß die Veränderungen dẹ Milz den Leberzirrhosen vorausgehen. In dieser Beziehung sind die Worte von $R o c h$ (a. a. O.) charakteristisch: ,Es gibt viele klinische Beobachtungen, die darauf hinweisen, $\mathrm{daB}$ die Milzveränderungen den Leberzirrhosen vorausgehen." Wir müssen daher voraussetzen, daß der Alkohol nicht direkt auf das Lebergewebe einwirkt. Er verursacht eine Leberzirrhose vermittels der Erythrophagen aus der Milz, die sich unter dem Einflusse dieses Giftes in den Malpighischen Körperchen stark vermehren und teils in der Milz selbst zerfallen, wobei es dann zu einer Vergrößerung dieses Organs kommt, teils in der Leber zugrunde gehen, in der dann eine entzündliche Proliferation des interlobulären Bindegewebes entstehen kann, abhängig von der Zahl der zerfallenen Erythrophagen. Der Unterschied zwischen dem Organismus des Tieres, bei dem durch den Alkohol keine Leberzirrhose entsteht, und dem des Menschen besteht darin, daß die Erythrophagen des Menschen diesem Gift gegenüber mehr widerstandsfähig sind und in großer Zahl mit dem Blutstrom in die Kapillaren der Leberläppchen gelangen können, während die Erythrophagen der Tiere und der Menschen, die nicht zu Zirrhosen disponiert sind, fast alle in der Milz selbst zerfallen, so daß nur ein geringer Teil in die Leber gelangt, wo sie wegen ihrer geringen Anzahl keine Proliferation des interlobulären Bindegewebes hervorrufen können.

In bezug auf das tuberkulöse Virus unterscheiden sich der Mensch und das Tier nicht wesentlich voneinander: die Erythrophagen sind diesem Virus gegenüber offenbar bei beiden gleich widerstandsfähig und gelangen in gleich großen Mengen in die Leber, wo sie durch ihre starken Zerfallsprodukte eine Entzündung des Bindegewebes und mitunter auch zirrhotische Prozesse auslösen.

Selbstverständlich müssen wir die individuellen Unterschiede berücksichtigen, die in bezug auf die einzelnen Zellen bei derselben Tierart wie auch in bezug auf die Quantität und Qualität des Giftes selbst bestehen.

Auf Grund der obigen Ausführungen können wir annehmen, daß die Zahl der Gifte, die dem Pyrodin, Alkohol und dem tuberkulösen Gifte analog wirken und zu Anämien und verschiedenen Veränderungen in bestimmten Organen führen, keine geringe sein $\mathrm{muß}$.

Im allgemeinen können wir erwarten, daß die nach obigem Typus der Erythrophagie wirkenden anämisierenden Gifte in folgenden Fällen eine Rolle spielen: 
1. bei vielen Infektionskrankheiten (Tuberkulose, Syphilis, Aussatz, Malaria, Abdominaltyphus usw.);

2. bei chronisehen Vergiftungen (Alkohol u. a.);

3. bei Anwesenheit von Darmparasiten (z. B. bei Bothriocephalus latus ${ }^{1}$ ));

4. bei bösartigen Neubildungen (die Anämie der Krebskranken ist eine beständige Erscheinung);

5. bei den erhöhten Gährungserscheinungen im Darm und bei Koprostasen (vgl. Grawit z a. a. O. S. 233).

Selbstredend bedürfen die soeben aufgestellten Thesen einer strengen Kontrolle und weiteren Ausarbeitung nach der früher angedeuteten Richtung hin in großen und wohleingerichteten Laboratorien, also unter günstigeren Bedingungen, als sie mir zu Gebote standen. Ich hoffe, in der nächsten Zeit die mir gestellte Aufgabe erfüllen zu können, ich möchte aber schon jetzt meine Ansichten über die in P. 5 angeführten Anämien, die im Darm durch Bildung von anormalen Fäulnisprodukten und durch dieselben erzeugten pathologischen Veränderungen klarlegen.

L u igi d' A mato ${ }^{27}$ stellte sich die Aufgabe, bei den Tieren eine Leberzirrhose hervorzurufen. Da seine Vorgänger, welche verschiedene Gifte, namentlich Alkohol, benutat hatten, negative Resultate erzielten, und es anderseits bekannt ist, daß bei allen Fällen von Leberzirrhosen, auch mehr oder weniger stark ausgesprochene Veränderungen des Magendarmkanals beim Mensehen vorkommen, kam dieser Autor auf den Gedanken, ob nicht die Entzündung des Bindegewebes der Leber und die sich entwickelnde Zirrhose eine Folge der Aufsaugung der Zersetzungsprodukte des Magendarminhalts sei. Zu diesem Zweck hat er an Kaninchen und Hunden zahlreiche Versuche angestellt, indem er sie mit Fäulnisprodukten des Ochsenfleisches oder mit Buttersäure, die beständig bei der Darmfäulnis auftritt, vergiftete.

Bei allen diesen Versuchen, die verschieden lange Zeit, mitunter auch sehr lange durchgeführt wurden, gelang es dem Autor kein einziges Mal, eine richtige Leberzirrhose, wie beim Menschen, hervorzurufen. Das höchste, was er dabei erzielte, war eine ganz geringe, kleinzellige Infiltration, die unmöglich mit einer Leberzirrhose identifiziert werden konnte. Dagegen waren die Veränderungen in der Leber und Milz sehr interessanter Natur. Leider hat d' A $m$ a t o bei seinen Versuchen etwaige Veränderungen des Blutes und den Zustand des Knochenmarks nicht berücksichtigt.

Die Veränderungen der Milz bestehen im folgenden. Es besteht meistenteils eine sehr starke Hyperämie und Reichtum an Blutpigment; bei einigen Versuchen traten sehr große Zellen auf, welche Blutpigment enthielten; es bestand eine mehr oder weniger reichliche Entwicklung von Bindegewebe und eine fast in allen Fällen obligatorische Hyperplasie der M a l p i g h i schen Körperchen. In einem Falle (Versuch 9 mit Buttersäure, S. 451) hebt der Autor hervor, daß ,in einigen $\mathrm{M}$ a $\mathrm{l} \mathrm{p}$ i g h i schen Körperchen die lymphoiden Zellen verschwunden und durch größere uninukleäre ersetzt seien".

Es erwiesen sich folgende Veränderungen in der Leber:

1. Eine mehr oder weniger entwickelte zellige Infiltration des interlobulären Bindegewebes.

2. Die Veränderungen in den Leberzellen beziehen sich auf die peripherischen Partien der Läppchen: eine Vakuolisation der Leberzellen, die beständig angetroffen wird und mitunter so stark ausgebildet ist, daß das Protoplasma bloß ein feines Netz bildet; die Kerne sind dabei unverändert; die Zellen färben sich oft schlecht, sie sind von den Balken abgelöst, manehe nekroti-

1) G r a w i t z faßt die Wirkung des von diesem Parasiten produzierten Giftes als eine plasmotrope auf. 
siert. Stellenweise betrifft die Nekrose ganze Gruppen von Zellen. Es befindet sich in ihnen viel sotbraunes Blutpigment (S. 449).

3. Es traten in den peripherischen Partien der Läppchen Gebilde auf, die der Autor für „Pigmentklumpen" hält. Diese Klümpchen sind auf der Zeichnung I der Tafel XIII abgebildet. D'A m a t o hat hier unsere Erythrophagen mit allen ihren charakteristischen Merkmalen abgebildet.

4. Eine wenig entwickelte Hyperämie.

5. Mitunter bestand eine Thrombose der zentralen Venen; es ist jedoch nicht gesagt, wodurch diese Thrombose zustande kam.

Aus dieser Beschreibung der Veränderungen in der Milz und Leber, die infolge der Vergiftung mit den Fäulnisprodukten des Darminhalts auftraten, ist zu ersehen, daß d'A m a t o es mit einem erhöhten Zerfall der roten Blutkörperchen durch die Erythrophagen zu tun hatte, die in den Malpigh i schen Körperchen der Milz proliferieren. Infolge des erhöhten Zerfalls der Erythrophagen in der Milz kam es zu einem Reichtum an Blutpigment in derselben und zu der Entwicklung einer Splenomegalie. Die vakuolenhaltigen Zellen in der Peripherie der Leberläppchen, ihre mehr oder weniger ausgesprochene Nekrose, ihr Gehalt an Blutpigment „Pigmentklumpen" und Thromben der Zentralvenen - alles dieses weist darauf hin, daß dieser Autor auch in der Leber Erythrophagen gesehen hat, nur schreibt er die sie charakterisierenden Eigenschaften den Leberzellen zu, wahrscheinlich deshalb, weil sie infolge ihrer Wandständigkeit den Leberzellen eng anliegen. In einigen Fällen freilich sah sie der Autor ,,abgelöst" von den Leberbalken; doch sind das natürlich Erythrophagen, die in den Kapillaren frei liegen.

An der Hand dieser für uns höchst interessanten Arbeit von Luigi d'A m a to war es uns sehr wichtig, den Zusammenhang zwischen der Erscheinung der erhöhten Erythrophagie und der Resorption der Produkte einer anormalen Speisezersetzung bei den Magen-Darmkrankheiten festzustellen.

Wir müssen daher einen der $\mathrm{Hauptgründe} \mathrm{der} \mathrm{primären} \mathrm{An} \mathrm{-}$ ä $\mathrm{m}$ i e $\mathrm{n}$ und der durch sie verursachten Veränderungen in der Milz und Leber sei es eine Leberzirrhose oder Splenomegalie, perniziöse essentielle Anämie oder der Symptomenkomplex der Bantischen Krankheit - in allen diesen Fällen i n chronischen Funktionsstörungendes Magen-Darmtractus und der dabei stattfindenden Resorption der Fäulnisprodukte der Speisen s u chen. Infolgedessen müssen wir den Therapeuten aufs dringendste empfehlen, in den geeigneten Fällen ihr Hauptaugenmerk auf den Zustand des Magenund Darmkanals ihrer Patienten bei den obengenannten vier Formen der primären Anämien zu lenken, eingedenk des Wahlspruches des großen Klinikers L e y d e n : Qui bene nutrit, bene medetur. Unserer Anschauung nach gebührt auch dem Laktobazillin von $\mathrm{Mets} \mathrm{ch} \mathrm{n} \mathrm{ik} \mathrm{ow} \mathrm{ein} \mathrm{Ehrenplatz} \mathrm{unter} \mathrm{den} \mathrm{therapeutischen}$ Maßnahmen bei diesen Krankheiten.

In einigen Fällen kann die Exstirpation der Milz, als des Hauptherdes, an dem die Erythrozyten zugrunde gehen, Heilung bringen. Wie bekannt, hat B a n ti als erster diese Operation vorgeschlagen. 
Als Resultat unserer Abhandlung ergeben sich folgende hauptsächlichsten Grundfolgerungen:

1. Der Prozeß der Zerstörung der Blutkörperchen unter normalen Verhältnissen geschieht durch besondere Zellen - Erythrophagen, die in der Milz die Formelemente des Blutes, hauptsächlich die roten Blutkörperchen, verschlingen. Die Zellen zerfallen teils in der Milz selbst, zum größten Teil gelangen sie mit dem Blutstrom in die Leber, wo sie endgültig zugrunde gehen und die Zerfallsprodukte der in ihnen stattgefundenen Erythrozytenzerstörung den Leberzellen übermitteln, die sie zu Galle verarbeiten. Ohne diese merkwürdigen Vorrichtungen können wir uns den Mechanismus der Aufnahme der roten Blutkörperchen aus den Leberkapillaren nicht vorstellen. Als Ersatz für die verloren gegangenen Erythrozyten produziert das Knochenmark neue.

2. Bei pathologischen Zuständen, die eine Anämie zur Folge haben, geschieht der Prozeß der Verschlingung der roten Blutkörperchen durch die Erythrophagen im verstärkten Maße.

3. Die B a n ti sche Krankheit, Leberzirrhose, primäre Splenomegalie und perniziöse Anämie sind keine selbständigen Krankheiten: sie müssen als eine gemeinsame Gruppe der primären Anämien aufgefaßt werden und unterscheiden sich voneinander in bezug auf ihre Krankheitsäußerungen bloß quantitativ: wenn im klinischen Krankheitsbilde die Veränderungen des Blutes am meisten ausgeprägt sind, sprechen wir von perniziöser Anämie; bei dem Vorwiegen von Erscheinungen, die von einer erhöhten Entwicklung von Bindegewebe in der Leber abhängig sind, nennen wir diese Krankheit eine Leberzirrhose; wenn uns am meisten die MilzvergröBerung auffällt, während die Erscheinungen von seiten des Blutes und der Leber im klinisehen Bilde zurücktreten -, diagnostizieren wir eine primäre Splenomegalie, während eine Kombination all dieser klinischen Symptome als B a n t i sche Krankheit bezeichnet wird.

4. Jede Leberzirrhose entsteht durch eine entzündliche Reizung des Bindegewebes der G lis s o n schen Kapsel, und zwar durch die Produkte des Zerfalls der Erythrophagen samt ihrem Inhalt; dieser Prozeß findet hauptsächlich in den peripherischen Teilen der Leberläppchen statt.

5. Die Splenomegalie entwickelt sich bei den anämischen Zuständen hauptsächlich infolge von Bindegewebswucherungen des Milzstromas. Diese Bindegewebswucherung wird ausgelöst dureh die Zerfallsprodukte der roten Blutkörperchen infolge der Tätigkeit der Erythrophagen.

6. Als Bildungsstätte der Erythrophagen sind die Malpig hischen Körperchen anzusehen; die erhöhte Vermehrung dieser Elemente wird durch verschiedene Gifte, die entweder im Körper selbst produziert oder von außen zugeführt werden, hervorgerufen.

7. Der sogenannte hämatogene Ikterus, der infolge des erhöhten Zerfalls der roten Blutkörperchen in den Erythrophagen zustandekommt, findet sehr leicht seine 
Erklärung in osmotischen Vorgängen, die zwischen den Leberzellen einerseits und den Erythrophagen andrerseits statthaben.

8. Die Veränderungen des Blutes bei den primären Anämien finden in einer Verminderung der Zahl der roten Blutkörperehen, die in der Milz und der Leber infolge der erhöhten Tätigkeit des Protoplasmas der Erythrophagen zugrunde gehen, ihren Ausdruck. Andrerseits treten dabei Veränderungen der qualitativen Zusammensetzung des Blutes auf, charakterisiert durch den Ersatz der abgestorbenen Erythrozyten durch neue, vom Knochenmark beschleunigt produzierte Zellelemente. Bei einer solchen verstärkten Produktion von Erythrozyten treten im Blute Jugendformen auf: polychromatophile, Erythroblasten, Makro- und Mikrozyten; die Poikilozyten müssen allem Anschein nach ebenfalls zu den Jugendformen gezählt werden.

9. Das tuberkulöse Gift ruft, im Kampfe mit der Infektion, eine verstärkte Proliferation von Phagozyten in den Malpigh ischen Körperchen der Milz hervor, die zugleich als Erythrophagen ihre Wirkung mit den daraus resultierenden Folgen entfalten: einer Anämie, Milzvergrößerung und Leberveränderungen von zirrhotischem Charakter.

10. Das tuberkulöse und syphilitische Gift (sowie auch einige andere) rufen eine erhöhte Bildung von Phagozyten (resp. Erythrophagen) hervor; diese erhöhte Tätigkeit wird nicht nur durch Vermehrung der Elemente der M al pig h i schen Körperchen der Milz, sondern auch durch die Vermehrung der Zellen der Lymphknötchen hervorgerufen; in letzteren tritt im gegebenen Falle gleichfalls eine Vermehrung dieser „Phagozyten ohne Auswahl" ein.

\section{Erklärung der Abbildungen auf Taf. II. III. IV.}

Fig. 1. Drei Erythrophagen in Venul. lienal. bei. B a $\mathrm{n} t \mathrm{i}$ scher Krankheit: zwei mit Erythrozyten, innerhalb dritt. ein Mononukleär. Ein Mikrophotogramm bei 1200 VergröBerung.

Fig. 2. Voriges Präparat bei schwacher Vergrößerung.

Fig. 3. Erythrophagen in Leberkapillaren bei B a $\mathbf{n}$ i ischer Krankheit (Mikrophotogramm).

Fig. 4. Erythrophagen in Leberkapillaren bei $\mathrm{B}$ antischer Krankheit. Fixation in Azeton, Färbung mit Azur-Eosin (Zeichnung).

Fig. 5. Erythrophagen der Leber in physiologischer Kochsalzlösung.

Fig. 6. Erythrophagen der Leber bei Morbus Bantii. Eisenreaktion mit Nachfärbung mit Neutralrot u. Pikrinsäure.

Fig. 7. Erythrophagen der Milz bei Lungentuberkulose.

Fig. 8. Erythrophagen der Leber bei Lungentuberkulose.

Fig. 9. Erythrophagen in Milz bei Splenomegalie (Typus G a u ch e r). Eine Zeichnung von Prof. Schlagenhaufer aus Virch. Arch. (Bd. 187).

Fig. 10. Erythrophagen einer Lymphdrüse bei Splenomegalie (Typ. Gau cher), nach Prof. $\mathrm{S}$ ch I a ge $\mathrm{n}$ h a u f er (ibid.).

Fig. 11. Erythrophagen in Milz eines Kaninchens bei Pyrodinvergiftung.

Fig. 12. Vermehrung von lymphoiden Elementen der $\mathrm{M} \mathrm{a} \mathrm{l} \mathrm{p} \mathrm{i} \mathrm{g} \mathrm{h} \mathrm{i} \mathrm{schen} \mathrm{Körperchen} \mathrm{in} \mathrm{Kanin-}$ chenmilz unter Pyrodineinwirkung.

Fig. 13. Umwandlung von lymphoiden Elementen der $\mathrm{M} \mathrm{a} \mathbf{l ~ p ~} \mathrm{g} \mathrm{h}$ i schen Körperchen der Milz in Erythrophagen. 


\title{
Literatur.
}

1. Qu incke. Deutsch. Arch. f. klin. Med. Bd. 20 u. 25 u. Ztbl. f. d. med. Wiss. 1887 Nr. 47. - 2. B a n t i, Splenomegalie mit Leberzirrhose, Zieglers Beitr. z. path. Anat. u. allg. Path. Bd. 24, 1898. - 3. F e lix K l o s t o c k, Úber Milztumor, Ikterus und Aszites bei Leberzirrhose, Virch. Arch. Bd. 187, 1907. - 4. E. Z i e g 1 e r, Lehrbuch der speziellen pathologischen Anatomie, Jena 1906. - 5. Sil b e r m a n.n, Berl. klin. Wschr. 1886, S. 473. 6. R o s e nst e i n, Utber chron. Leberentzündung, Ref. f. inn. Med. 1892. - 7 W l a j e w, Ửber einige Veränderungen des Blutes bei Erkrankungen der Leber ( $\mathrm{E} G \mathrm{r}$ a w itz, a. a. o.). -8. Graw it z, Klinische Pathologie des Blutes, Leipzig 1906. - 9. B l e i c hr oe d e r, Uther Leberzirrhose und Blutkrankheiten, Virch. Arch. Bd. 177, 1904. - 10. B o r i s s o v a, Beiträge zur Kenntnis der B a n t i schen Krankheit und Splenomegalie, Virch. Arch. Bd. 172, 1903. 11. Зе леневъ. Сифилитич. хлоранемія. Диссерт. Кіевъ. - 12. Bartel und N e u man n, Lymphozyt und Tuberkelbazillus, Ztbl f. Bakteriol. Bd. 40, H. 4, 1905. - 13. M o u is s e t et B o n n a m o u r. Du foie des tuberculeux Rev. de méd. T. 24, 1904. - 14. N i k i f o r of f, Phagozytenkampf bei Rückfalltyphus, Zieglers Beitr. XII, 1892. - 15. M. R o s c h, Relations du foie et de la rate en pathologie, XI Congrès francais de Médecine, Paris 13-15 Octobre 1910. - 16. G a u c h e r, Splenomegalie primitive, Thèse de Paris, 1882. - 17. Prof. Dr. F r i e d r i c h $\mathrm{S}$ c h l a g e n h a u f er, Wien, Ứber meist familiär vorkommende histologisch charakteristische Splenomegalien (Typus G a u c h er), Virch. Arch. Bd. 187, 1907. - 18. R. H e i n z, Über Blutdegeneration und Regeneration, Zieglers Beitr. Bd.29, 1901. - 19. V. L e u b e, Utber einen Fall von rapid verlaufener schwerer Anämie mit gleichzeitiger leukämischer Beschaffenheit des Blutes (Grawitz, a. a. 0. S. 322). - 20. W. Donitz, D. Klin. Bd. 1. - 21. C. S tern berg, Über eine eigenartige, unter dem Bilde der Pseudoleukämie verlaufende Tuberkulose des lymphat. Apparates. Ztschr. f. Heilk. 1897 ( $\mathrm{G}$ x a witz S. 479). - 22. L ö w e n b a c h, Beitrag zur Histologie der gummösen Lymphome. Arch. f. Derm. u. Syph. Bd. 48, 1899 ( Gr a w it z a. a. O. S. 482). - 23. As kanazy, Verh. d. D. Path. Ges. 1904 (Grawitz, a. a. 0. S. 478). 24. F i s c h e r, ttber malignes Lymphom, Arch. f. klin. Chir. Bd. 55 (G r a w it z, a. a. O. S. 478). - 25. S a b x a zés, Hématologie clinique. Paris 1900 (ibid.). - 26. D o m in i c i, Arch. de médecine expérim. I. 13, 1901, p. 32. - 27. L u i g i d'A m a t o, țber experimentelle vom Magendarmkanal aus hervorgerufene Veränderungen der Leber und über dabei gefundene Veränderungen der übrigen Bauchorgane. Virch. Arch. Bd. 187, 1907.

\author{
V. \\ Zur Histologie der Nenrohypophyse. \\ (Aus dem Pathologischen Institut der Universität Königsberg i. Pr.) \\ Von \\ Privatdozent Dr. S t u m p f, Breslau. \\ Mit 6 . Textfiguren.
}

In einer vor einiger Zeit erschienenen Arbeit hat $\mathrm{Koh} \mathrm{n}^{\mathbf{1}}$ ) zusammengestellt, was bis dahin über die feinere Histologie des Hinterlappens der Hypophyse bekannt war, ohne daß jedoch wohl in seiner Absicht lag, alle Einzelheiten auszuführen. Er hat vielmehr sein Hauptinteresse dem daselbst vorkommenden Pigment zugewandt und das übrige kürzer behandelt. Die Literatur findet sich dort, so daß sich erübrigt, sie im einzelnen zu wiederholen.

Ich habe eine große Reihe von Hypophysen des Menschen der verschiedensten Altersstufen untersucht, hauptsächlich um über das Verhalten der Neuroglia in

1) Kohn, Alfred, Utber das Pigment in der Neurohypophyse des Menschen. Arch. f. mikr. Anat. Bd. 75, S. 337 f. 